\title{
Sediment transport on the Palos Verdes shelf, California
}

\author{
Bénédicte Ferré ${ }^{\mathrm{a}, 1}$, Christopher R. Sherwood ${ }^{\mathrm{a}, *}$, Patricia L. Wiberg ${ }^{\mathrm{b}}$ \\ a US Geological Survey, 384 Woods Hole Road, Woods Hole, MA 02543-1598, USA \\ ${ }^{\mathrm{b}}$ Department of Environmental Sciences, University of Virginia, Charlottesville, VA 22904-4123, USA
}

\section{A R T I C L E I N F O}

\section{Article history:}

Received 24 November 2009

Accepted 21 January 2010

Available online 1 February 2010

\section{Keywords:}

Sediment transport

Erodibility

DDT

PCBs

Numerical model

USA

California

Palos Verdes

\begin{abstract}
A B S T R A C T
Sediment transport and the potential for erosion or deposition have been investigated on the Palos Verdes (PV) and San Pedro shelves in southern California to help assess the fate of an effluent-affected deposit contaminated with DDT and PCBs. Bottom boundary layer measurements at two 60-m sites in spring 2004 were used to set model parameters and evaluate a one-dimensional (vertical) model of local, steady-state resuspension, and suspended-sediment transport. The model demonstrated skill (Brier scores up to 0.75) reproducing the magnitudes of bottom shear stress, current speeds, and suspended-sediment concentrations measured during an April transport event, but the model tended to underpredict observed rotation in the bottom-boundary layer, possibly because the model did not account for the effects of temperature-salinity stratification. The model was run with wave input estimated from a nearby buoy and current input from four to six years of measurements at thirteen sites on the 35- and 65-m isobaths on the PV and San Pedro shelves. Sediment characteristics and erodibility were based on gentle wet-sieve analysis and erosion-chamber measurements. Modeled flow and sediment transport were mostly alongshelf toward the northwest on the PV shelf with a significant offshore component. The 95th percentile of bottom shear stresses ranged from 0.09 to $0.16 \mathrm{~Pa}$ at the 65-m sites, and the lowest values were in the middle of the PV shelf, near the Whites Point sewage outfalls where the effluent-affected layer is thickest. Long-term mean transport rates varied from 0.9 to 4.8 metric tons $\mathrm{m}^{-1} \mathrm{yr}^{-1}$ along the 65-m isobaths on the PV shelf, and were much higher at the 35-m sites. Gradients in modeled alongshore transport rates suggest that, in the absence of a supply of sediment from the outfalls or PV coast, erosion at rates of $\sim 0.2 \mathrm{~mm} \mathrm{yr}^{-1}$ might occur in the region southeast of the outfalls. These rates are small compared to some estimates of background natural sedimentation rates $\left(\sim 5 \mathrm{~mm} \mathrm{yr}^{-1}\right)$, but do not preclude higher localized rates near abrupt transitions in sediment characteristics. However, low particle settling velocities and strong currents result in transport length-scales that are long relative to the narrow width of the PV shelf, which combined with the significant offshore component in transport, means that transport of resuspended sediment towards deep water is as likely as transport along the axis of the effluent-affected deposit.
\end{abstract}

Published by Elsevier Ltd.

\section{Introduction}

\subsection{Background and previous studies}

Sediment on the Palos Verdes (PV) shelf offshore of Los Angeles CA (Fig. 1) has been contaminated with the pesticide dichlorodiphenyltricloroethane (DDT), polychlorinated biphenyls (PCBs), metals, and other chemicals that were discharged through the Whites Point outfalls from the Joint Water Pollution Control Plant (JWPCP) operated by Los Angeles County Sanitation Districts (LACSD). Discharge of solids and contaminants from JWPCP began in 1937 and peaked around 1971, when solids discharge was

\footnotetext{
* Corresponding author. Tel.: +1 5084572269 ; fax: +15084572310. E-mail addresses: benedicte.ferre@uit.no (B. Ferré), csherwood@usgs.gov (C.R. Sherwood), pw3c@virginia.edu (P.L. Wiberg).

${ }^{1}$ Present affiliation: University of Tromsø, Norway.
}

167,000 metric tons $\mathrm{yr}^{-1}\left(\mathrm{tyr}^{-1}\right)$ and DDT discharge was about $21 \mathrm{tyr}^{-1}$ (Stull et al., 1996). Solids discharge in 2006 was less than $7000 \mathrm{tyr}^{-1}$, and DDT levels in the effluent have been below the National Pollutant Discharge Elimination System (NPDES) concentration limit of $0.029 \mathrm{~g} \mathrm{~m}^{-3}$ since 1989 and, since 2003, have been below reporting limits $\left(5 \times 10^{-4} \mathrm{~g} \mathrm{~m}^{-3}\right)$. PCB levels have been below reporting limits since 1985 (LACSD, 2004).

Solids from the outfalls have combined with sediment from other sources (most notably, erosion at the toe of the Portuguese Bend landslide) to form an effluent-affected deposit on the PV shelf covering more than $40 \mathrm{~km}^{2}$, and up to $0.60 \mathrm{~m}$ thick and containing a total volume of more than 9 million $\mathrm{m}^{3}$ of sediment (Lee et al., 2002; Murray et al., 2002). Contamination concentrations in this deposit are lowest in surface sediment (top 5-20 cm of the deposit) and much higher in the older and more deeply buried layers. Analyses of the DDT profiles in LACSD core samples obtained every two years since 1981 indicate that DDT inventories are declining in the effluent-affected deposit and that DDT 
concentrations are falling faster in surface sediment ( $\sim$ top $10 \mathrm{~cm}$ ) than in deeper sediment (Sherwood et al., 2002, Sherwood et al., 2006a; Eganhouse and Pontolillo, 2008). These analyses also indicate twenty-year sediment accumulation rates of $\sim 0.2-1.5 \mathrm{~cm}$ $\mathrm{yr}^{-1}$ over much of the deposit. However, the most recent unpublished data from LACSD (Sherwood et al., 2006a) suggest that accumulation rates are generally decreasing and the southeast edge of the effluent-affected deposit may be eroding. The southeast portion of the deposit is also the thickest and most contaminated part of the deposit, and there is concern that erosion there could introduce higher levels of DDT to surface sediment.

Contamination of the PV shelf and the surrounding Southern California Bight has motivated studies of the effluent-affected deposit and regional sediment dynamics for decades, beginning with those of Southern California Coastal Water Research Project (SCCWRP) and LACSD in the 1970s and 1980s. Early modeling efforts include those of Morel et al. (1975), Galloway (1979), Hendricks (1978, 1982, 1984, 1988), Logan et al. (1989), Hendricks and Eganhouse (1992), and Niedoroda et al. (1996). Wiberg et al. (2002) used a one-dimensional vertical (1DV) model (Smith, 1977; Kachel and Smith, 1989; Wiberg et al., 1994; Harris and Wiberg, 1997) calibrated with data from bottom boundary layer measurements to estimate the frequency and magnitude of resuspension and transport events at a 63-m site they designated B (our site B3, discussed in this paper; Fig. 1). This model was also used by Wiberg and Harris (2002) to study DDT desorption from resuspended sediment, and by Sherwood et al. (2002) to estimate long-term erosion and deposition trends determined from spatial variations in alongshore sediment transport on the 60-m isobath.

Since those studies, considerably more data have become available. The LACSD embarked on a long-term monitoring program on the PV and San Pedro shelves that provided up to six years of nearly continuous ADCP profiles and temperature records, and the USGS and SAIC measured bottom-boundary layer processes and mapped geotechnical properties in 2004. These new data, combined with information on waves, provided an opportunity to study spatial and seasonal variations in bottom stress and sediment transport.

\subsection{Site description}

The PV study area is a narrow section ( $\sim 3 \mathrm{~km}$ wide by $\sim 13 \mathrm{~km}$ long) of continental shelf (Fig. 1) on a headland that extends into

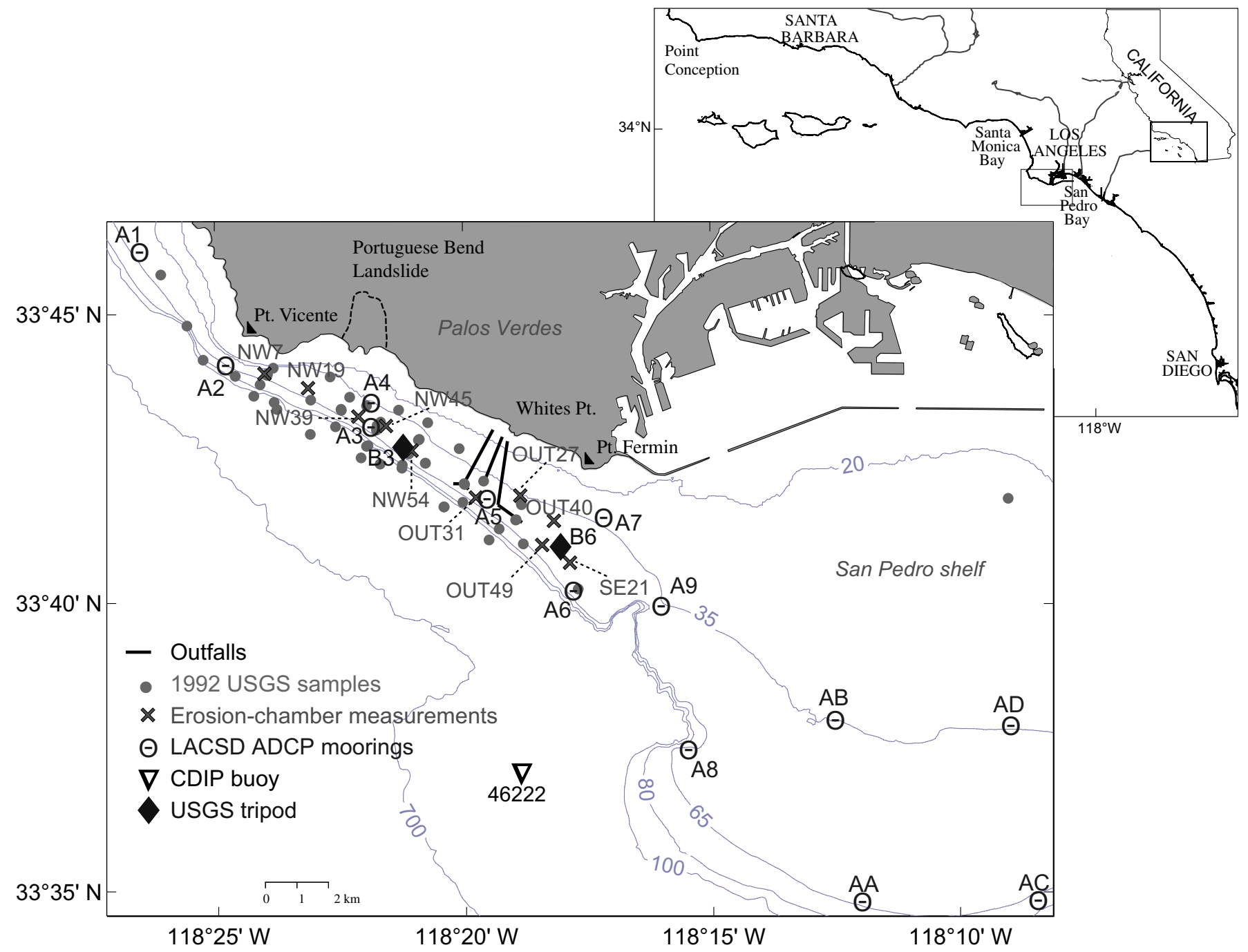

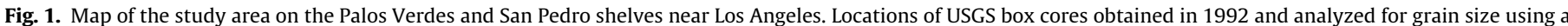

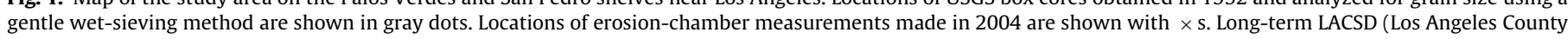

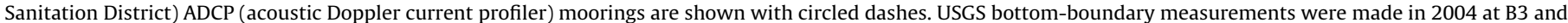
B6 (solid diamonds), and the location of CDIP Waverider buoy 46222 is marked with an triangle. Bathymetric contours are in meters. 
the Southern California Bight between San Pedro Bay to the southeast and Santa Monica Bay to the northwest. The shelf break occurs between 70 and $100 \mathrm{~m}$ water depth, where the bottom slope increases from $1^{\circ}$ to $3^{\circ}$ over the shelf to about $13^{\circ}$ over the slope (Lee, 1994). Sources of sediment supplied to the PV shelf are mainly local erosion of coastal bluffs and the toe of the Portuguese Bend landslide (Kayen et al., 2002), particulates discharged from the LACSD outfalls (Lee et al., 2002; Sherwood et al., 2002), and stormwater runoff (Jones et al., 2002). Some sediment is also provided by transport from the adjacent San Pedro and Santa Monica shelves, widely dispersed fluvial sediment, and in situ biological production.

Most of the PV shelf at depths between 50 and $70 \mathrm{~m}$ is covered with sandy silt (approximate mean size $4.5 \phi$ or $44 \mu \mathrm{m}$ ), with coarser material $(\sim 4.2 \phi$ or $60 \mu \mathrm{m})$ southeast of the outfalls and finer material northwest of the outfalls (Fig. 2; Drake, 1994; Drake et al., 2002). Coarser sediment (sand), rock outcrops, and kelp beds occur near shore (depths less than $20 \mathrm{~m}$ ). Silt and clay fractions (finer than $4 \phi$ ) form $10 \%$ to $20 \%$ of the sediment on the whole shelf, with greater values in the northwestern part of the mid and outer shelf. Sediment at 50-70-m depths is finest $\sim 1 \mathrm{~km}$ northwest of the outfalls and slightly coarser farther toward the northwest near Pt. Vicente. Sediment at 50-70-m depths is coarsest southeast of the outfalls off Pt. Fermin (Fig. 2; Drake, 1994; Drake et al., 2002; SAIC, 2005a).

More deeply buried sediment $(>15 \mathrm{~cm})$ in the effluentaffected deposit on the PV shelf is cohesive sandy mud. Cores and grab samples are dark gray or black, stiff, plastic material. Microscopic analyses performed by Drake et al. (2002) revealed that a significant fraction (6\%-43\%) of PV sediment was packaged in large (up to $125 \mu \mathrm{m}$ ), low-density $\left(1200-1500 \mathrm{~kg} \mathrm{~m}^{-3}\right.$ ) fecal pellets.

Currents on the PV shelf are influenced primarily by tides and regional-scale circulation (Hickey, 1992; Bray et al., 1999; Noble et al., 2002; Noble et al., 2009). Previous modeling efforts assumed that waves were the primary agent of sediment resuspension at $60 \mathrm{~m}$ on the PV shelf, and that resuspended sediment was transported by currents with a mean flow of $\sim 0.05 \mathrm{~m} \mathrm{~s}^{-1}$ toward the northwest. However, observations by Bogucki et al. (1997) on the PV shelf and by Noble and Xu (2003) at the shelf break in Santa Monica Bay suggest that solitary internal waves can resuspend and transport bottom sediment,
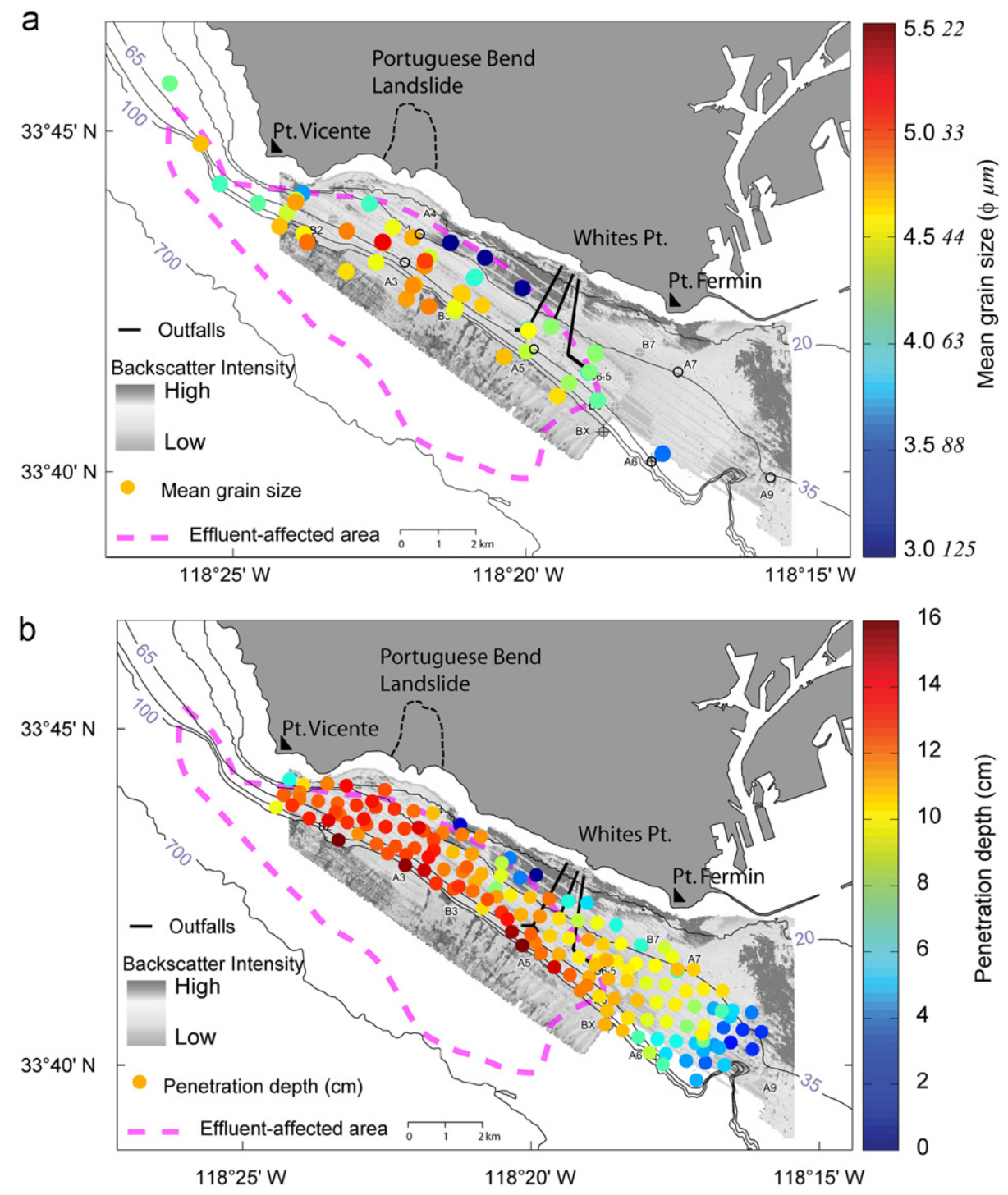

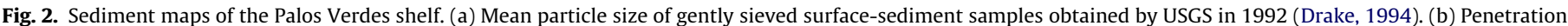

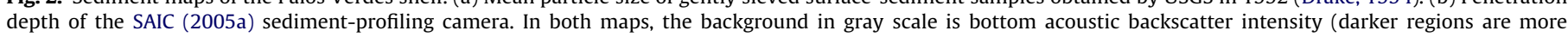

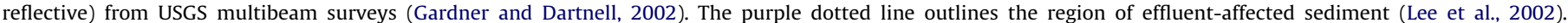
Bathymetric contours are in meters. 
and there is ample evidence in the LACSD ADCP data that episodic current events with significant shear occur frequently at some locations and may contribute to sediment resuspension and transport (Noble et al., 2009).

\subsection{Approach}

Our objective was to evaluate the frequency, magnitude, and direction of sediment transport on the PV shelf and the adjacent San Pedro shelf using the long-term ADCP current-meter observations made at nine sites by LACSD. In particular, we wanted to calculate alongshore gradients in sediment transport to determine whether material was eroding from the effluentaffected deposit without being replaced by sediment from the southeastern part of the PV shelf. We combined the ADCP measurements with wave observations and information on bottom sediment using a one-dimensional (vertical; 1DV) model for bottom boundary layer (bbl) flow and suspended-sediment transport. We evaluated model performance using bbl measurements made at two PV shelf sites, and then used the model to estimate long-term sediment-transport rates at all of the ADCP sites. We inferred deposition (or erosion) rates between sites by differencing the modeled transport rates. These indicated the influence of resuspension and transport on the fate of the effluent-affected deposit in the absence of other sources of sediment.

\section{Methods}

\subsection{One-dimensional (vertical) sediment-transport model}

Previous modeling efforts relied on relatively short (maximum one-year) current-meter measurements at three shelf locations (Noble et al., 2002) and a single four-month (winter 1992-1993) bbl data set at site B3 (site B of Wiberg et al., 2002) located about $5 \mathrm{~km}$ northwest of our site B6. The LACSD long-term monitoring program provided up to six years of nearly continuous ADCP profiles and temperature records at initially nine, then thirteen sites on the PV and San Pedro shelves. In addition, we made bbl measurements during a four-month experiment in late winterspring 2004 at sites B3 and B6 that can be compared with model calculations (SAIC, 2005b). New sources of information on waves, bottom sediment, and erodibility are also available, as discussed below.

We used these data in a one-dimensional vertical (1DV) model (Smith, 1977; Kachel and Smith, 1989; Wiberg et al., 1994; Harris and Wiberg, 1997; Wiberg et al., 2002) to calculate suspended-sediment transport rates. The model represented the frictional momentum balance in the bbl, assuming a steady balance between geostrophic flow and bottom stress, and using an eddy viscosity profile enhanced by wave-current interactions. Suspended sediment profiles were calculated assuming an instantaneous balance between upward diffusion and downward settling, with a near-bed reference concentration that depended on excess wave-current shear stress and sediment availability. The model required as input measurements of current velocity at a specific elevation above the bottom, near-bed wave-orbital velocities and associated wave period and direction, and bottomsediment characteristics (grain size distribution, critical shear stress, particle settling velocity, and erodibility parameters). The model returned estimates of combined wave and current bottom shear stress, and profiles of suspended sediment and velocity that extended from the seabed to mid-depth. Sedimenttransport rate was calculated as the product of velocity and suspended-sediment concentration, vertically integrated over the modeled profiles.

\subsection{Cohesive sediment dynamics}

Wiberg et al. (2002) modeled PV sediments as non-cohesive material whose availability was limited by the thickness of an active layer, and obtained good agreement among measured and modeled suspended-sediment concentrations. However, a cohesive bed usually becomes more difficult to erode as material is removed during erosion events (Type I erosion; Sanford and Maa, 2001), whereas the erodibility of non-cohesive material depends only on the characteristics of particles at sediment-water interface (Type II; Sanford and Maa, 2001) and does not necessarily change with depth in the bed. We modified the Wiberg et al (2002) model in order to constrain the amount of material available for erosion and applied it according to the characteristics of each site.

The mass of sediment available for suspension from cohesive beds was determined empirically from erosion-chamber measurements made on PV sediments in 2004. The active layer thickness $\delta_{\text {avail }}(\mathrm{m})$ was calculated as:

$\delta_{\text {avail }}=\frac{M}{\rho_{b} c_{b}}$

where $M$ is total mass eroded (per unit area) during the erosionchamber experiment $\left(\mathrm{kg} \mathrm{m}^{-2}\right.$; discussed in more detail below), $\rho_{b}$ the fraction-weighted mean sediment grain density $\left(\mathrm{kg} \mathrm{m}^{-3}\right)$, and $c_{b}$ the bed sediment concentration (1-porosity). The volume (per unit area of seafloor; $m$ ) of sediment available for suspension in each size class is $f r_{i} c_{b} \delta_{\text {avail }}$, where $f r_{i}$ is the fraction of sediment in size class $i$.

We assumed in our model calculations that the thickness of the bottom boundary layer was $10 \mathrm{~m}$. This prevented suspended sediment from mixing too high in the water column, improved model agreement with suspended-sediment observations, and partially mitigated the effects on bbl thickness, shear, and rotation that may have been caused by temperature-salinity stratification (Section 3.3.2) and that were not included in the model.

\section{Evaluation of the $1 \mathrm{DV}$ model with bottom boundary-layer measurements}

\subsection{Data}

The USGS deployed in February 2004 bottom-mounted tripods at sites B3 and B6 $\left(33.91^{\circ} \mathrm{N}, 118.36 \mathrm{~W}\right.$, and $\left.33.68^{\circ} \mathrm{N}, 118.31^{\circ} \mathrm{W}\right)$ respectively, located approximately $2 \mathrm{~km}$ northwest of the long Y-shaped JWPCP diffuser and $1 \mathrm{~km}$ south-southeast of the L-shaped diffuser, both at a nominal depth of $60 \mathrm{~m}$ (Fig. 1). The tripod at site B3 tipped over during deployment, but we were able to determine its orientation and recover usable data from a threeaxis acoustic Doppler velocimeter (ADV) measuring at $1.41 \mathrm{mab}$ (meters above the bottom), a transmissometer at $1.54 \mathrm{mab}$, and an acoustic backscatterance sediment (ABS) profiler that ended up measuring suspended-sediment concentrations between 1.61 and $1.67 \mathrm{mab}$. ADV data from the toppled tripod were reoriented by calculating the median of principal components for each burst and rotating the data set so that the smallest component was up and the two larger horizontal axes matched directions of those at site B6. High-quality data were obtained between 16 February and 25 June 2004 (Figs. 3 and 4).

Instruments on the B6 tripod included an upward-looking acoustic Doppler current profiler (ADCP) to measure velocity profiles, an ADV that measured velocity at $0.6 \mathrm{mab}$, a downward-looking 

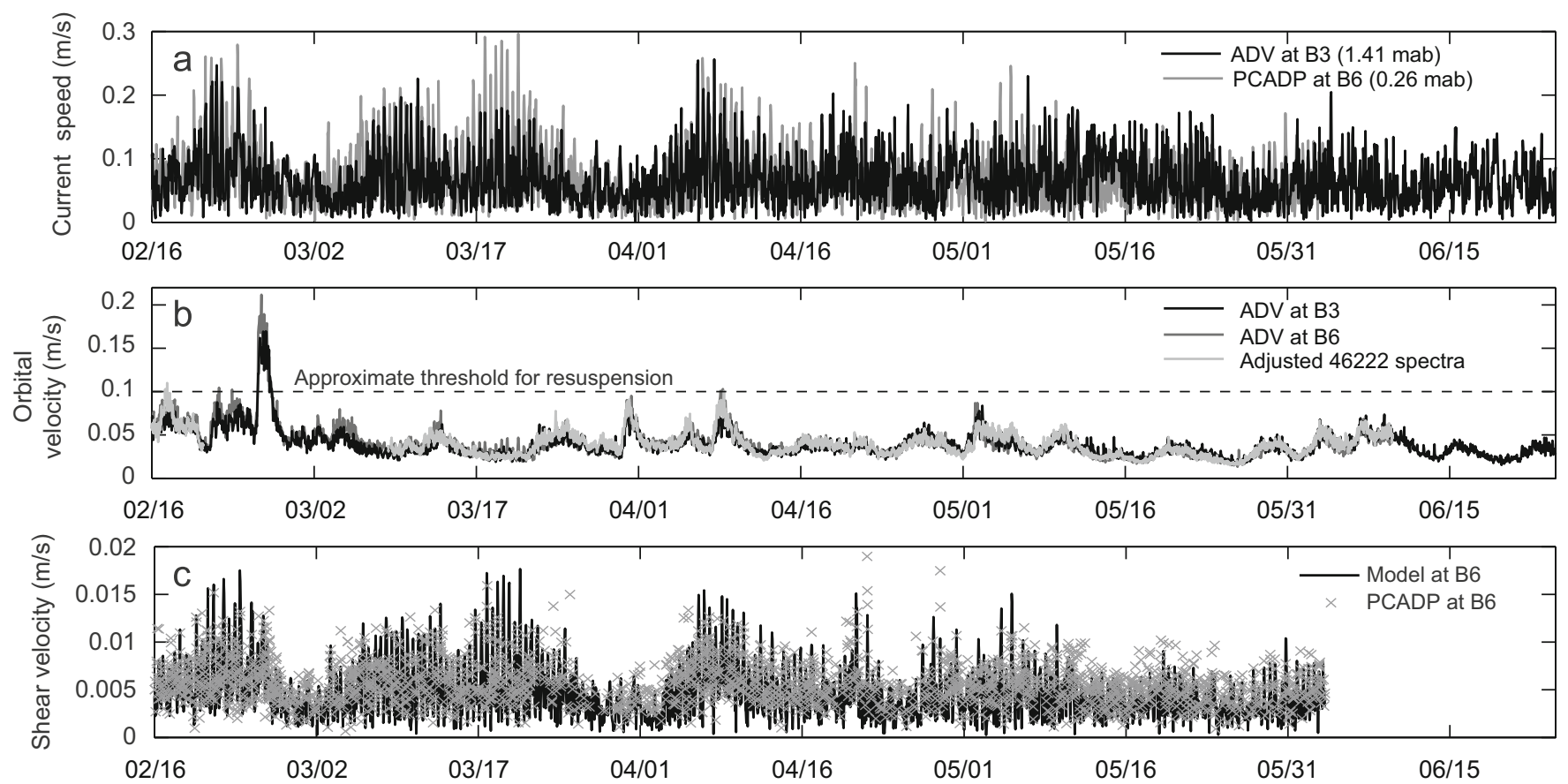

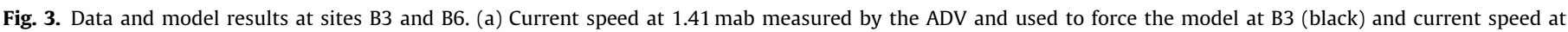

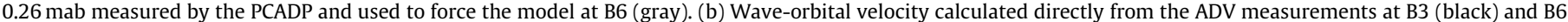

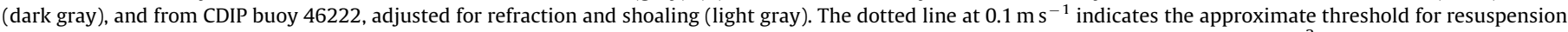

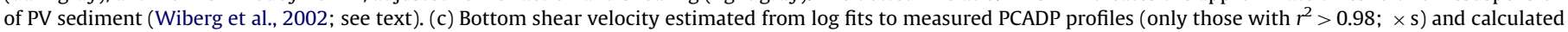
by the model (line).

pulse-coherent acoustic Doppler profiler (PCADP) to obtain profiles of horizontal velocity between $\sim 0.06$ and $\sim 0.76$ mab, a transmissometer to measure turbidity at $1.74 \mathrm{mab}$, and a downward-facing ABS profiler to obtain suspended-sediment profiles in the bottom $\sim 1$ mab (Table 1). High-quality data were obtained between 16 February and 4 June 2004 (Figs. 3 and 5).

Transmissometer data were converted to estimates of suspended-sediment concentration $C_{s}$ using $C_{s}=c_{p} / a$, where $C_{s}$ is in $\mathrm{kg} \mathrm{m}^{-3}, c_{p}$ the light attenuation in $\mathrm{m}^{-1}$, and $a$ a dimensional coefficient. We used $a=0.22 \times 10^{-3} \mathrm{~kg} \mathrm{~m}^{-2}$, based on a laboratory calibration of transmissometer data against suspended sediment concentration measured in pumped samples taken at the same levels by Wiberg et al. (2002) at site B3 (their site B) in 1992-1993. The transmissometer and ABS at both sites functioned for the entire deployment but the transmissometer data at site B3 after March 2nd were not usable (dotted line in Fig. 4b). We corrected for fouling of the transmissometer at site B6 beginning on April 26 (dashed line in Fig. 5a) by calculating and removing a linear increase in the measured signal, and replacing it with an estimated response (solid line in Fig. 5a). The ABS responses were calibrated in a laboratory tank at four suspended-sediment concentrations $(25,50$, 150 , and $250 \mathrm{~g} \mathrm{~m}^{-3}$ ) using sediment from the top $2 \mathrm{~cm}$ at the respective sites, both sampled on 4 August 2004.

\subsection{Model input}

The 1DV model requires as input values of steady horizontal current velocity at a specified elevation, near-bottom waveorbital velocity and associated period and direction, bottom roughness, and bed sediment characteristics. The source of each input is discussed below.

\subsubsection{Currents and wave-orbital velocities}

We used as input to the model hourly burst-mean current velocities recorded by the ADV (1.41 mab) at site B3 and the
PCADP (0.26 mab) at site B6 (Table 1, Fig. 3a). Current speeds ranged from $<0.01$ to $0.26 \mathrm{~ms}^{-1}$, with a mean of $0.07 \mathrm{~ms}^{-1}$ toward $284^{\circ} \mathrm{T}$ at site $\mathrm{B} 3$, and from $<0.01$ to $0.35 \mathrm{~m} \mathrm{~s}^{-1}$, with a mean of $0.07 \mathrm{~ms}^{-1}$ at site $\mathrm{B} 6$. There was excellent agreement (mean difference $\sim 0.006 \mathrm{~m} \mathrm{~s}^{-1}$ ) among contemporaneous burst-mean measurements from the ADV at $0.6 \mathrm{mab}$ and the corresponding PCADP bin at B6.

Near-bottom wave-orbital velocity $u_{b r}$ (Madsen, 1994) was determined from hourly ADV burst measurements of velocity both sites using the method described by Wiberg and Sherwood (2008). Wave period was determined from the frequencyweighted orbital velocity spectra (Madsen, 1994) and wave direction was set equal to the principal axes of current fluctuations in each burst. The representative orbital velocities $u_{b r}$ were similar at both sites (although slightly lower at site B3), and were generally less than $0.07 \mathrm{~m} \mathrm{~s}^{-1}$, exceeding for only a few hours the $0.1 \mathrm{~m} \mathrm{~s}^{-1}$ threshold used by Wiberg et al. (2002) to identify transport events (Fig. 3b; dashed line). (Note that Wiberg et al. (2002) used a threshold of $0.14 \mathrm{~ms}^{-1}$, defined in terms of the significant orbital velocity $u_{b s}=\sqrt{2} u_{b r}$; and we have converted that threshold to $u_{b r}$; see Wiberg and Sherwood, 2008). The mean ratio of burst-mean current speeds to orbital velocities was about 1.7 at both sites, indicating that conditions were mostly currentdominated, but currents were seldom sufficient to mobilize bottom sediment.

\subsubsection{Bottom roughness}

The model requires values for inner hydraulic roughness of the bed $z_{0}$, which is a function of bed material, small-scale bottom topography (ripples, biogenic features), and flow conditions including sediment movement. Although we could not directly measure $z_{0}$, we were able to estimate the friction velocity $u_{*}$ and apparent roughness $z_{0 a}$ of the bed from the PCADP measurements at B6, and use these to constrain $z_{0}$ at both sites. Apparent roughness $z_{0 a}$ is associated with overall drag of the bottom 

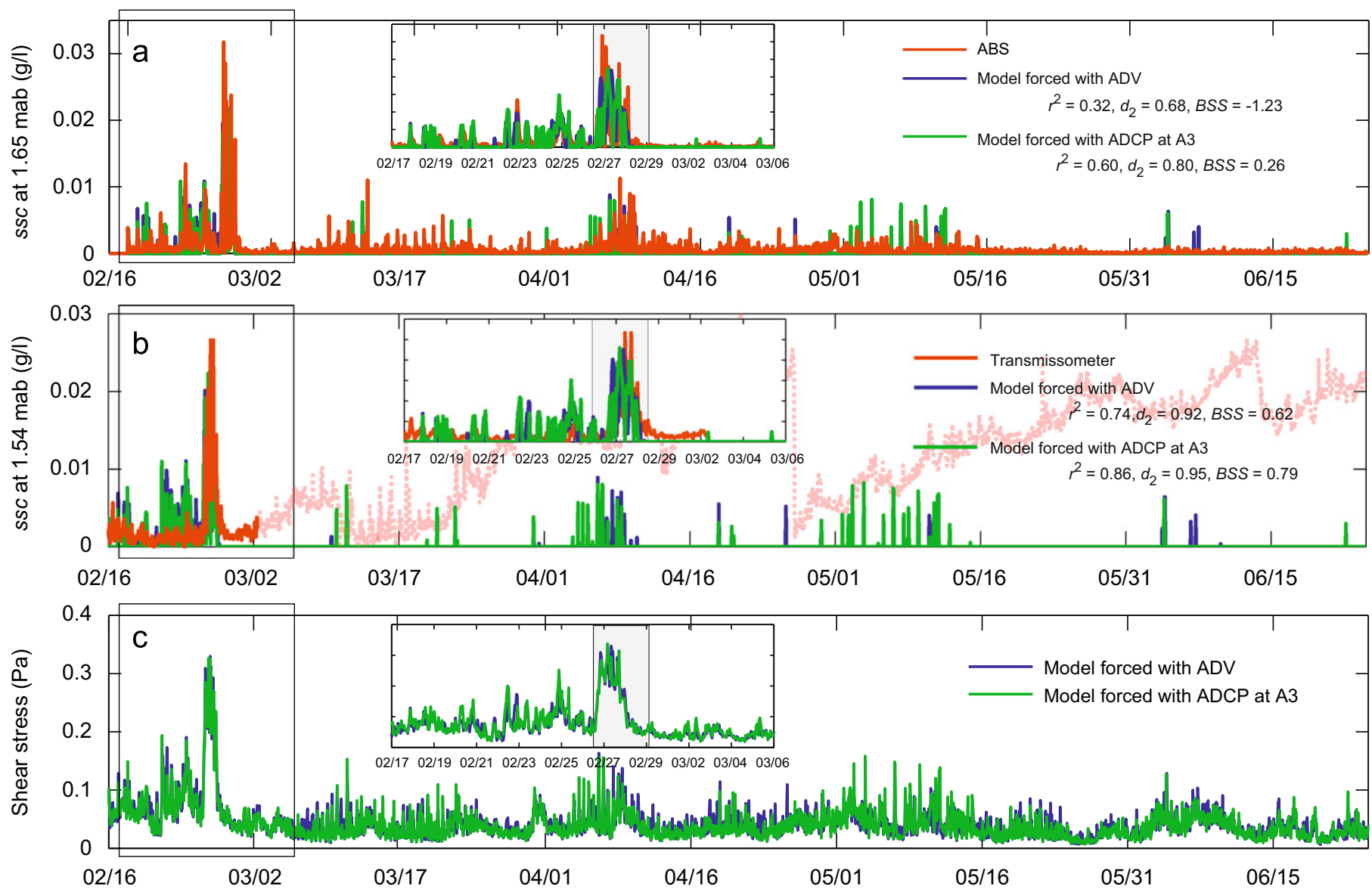

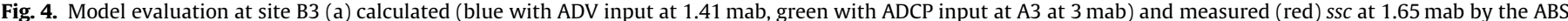

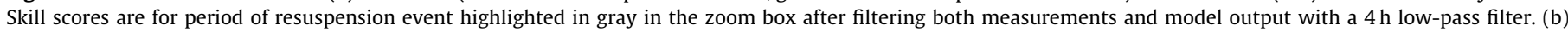

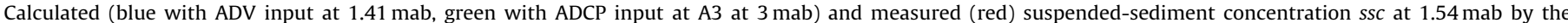

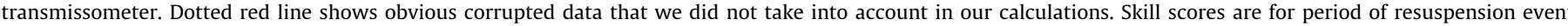

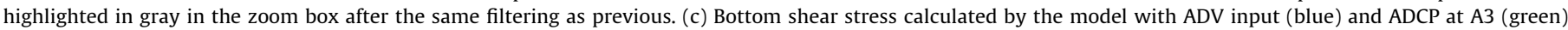

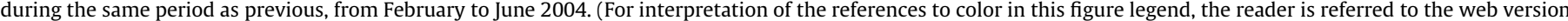
of this article.)

Table 1

Summary of instruments deployed at sites B3 and B6 from February to June, 2004

\begin{tabular}{|c|c|c|c|c|}
\hline Abbreviation & Description & $\begin{array}{l}\text { Measurement } \\
\text { elevations at B3 }\end{array}$ & Measurement elevations at B6 & Sampling schedule \\
\hline ADV & $\begin{array}{l}\text { Sontek/YSI Inc. acoustic Doppler } \\
\text { velocimeter, ocean model }\end{array}$ & $1.41 \mathrm{mab}$ & $0.6 \mathrm{mab}$ & $\begin{array}{l}12 \mathrm{~min} \text { at } 10 \mathrm{~Hz} \text { every hour and } 3 \mathrm{~min} \\
\text { at } 1 \mathrm{~Hz} \text { every } 0.5 \mathrm{~h}\end{array}$ \\
\hline PCADP & $\begin{array}{l}\text { Sontek/YSI Inc. } 1500-\mathrm{KHz} \text { pulse-coherent } \\
\text { acoustic Doppler profiler }\end{array}$ & - & $\begin{array}{l}\text { Mounted } 1.05 \mathrm{mab} \text {; data from } 0.76 \text { to } \\
0.06 \text { mab in } 0.1-\mathrm{m} \text { bins }\end{array}$ & $6 \mathrm{~min}$ at $0.5 \mathrm{~Hz}$ every $15 \mathrm{~min}$ \\
\hline $\mathrm{ADCP}$ & RD Instruments Inc. $300 \mathrm{kHz}$ Workhorse & - & $\begin{array}{l}\text { Mounted } 3.27 \mathrm{mab} \text {; data from } 7.5 \text { to } \\
63.5 \mathrm{mab} \text { in } 2-\mathrm{m} \text { bins }\end{array}$ & 3-min averages (60 pings each) \\
\hline ABS & Aquatec Aquascat $1,2.5$, and $5 \mathrm{MHz}$ & $1.61-1.67 \mathrm{mab}$ & $\begin{array}{l}\text { Mounted } 1.01 \mathrm{mab} \text {; data from } 0.99 \text { to } \\
0.004 \mathrm{mab}\end{array}$ & $6 \mathrm{~min}$ every $15 \mathrm{~min}$ \\
\hline Transmissometer & Cstar wavelength $650 \mathrm{~nm}$, pathlength $25 \mathrm{~cm}$ & $1.54 \mathrm{mab}$ & $1.74 \mathrm{mab}$ & Same as ADV \\
\hline Pressure sensors & Paroscientific digiquartz sensor & $1.42 \mathrm{mab}$ & $1.79 \mathrm{mab}$ & Same as ADV \\
\hline
\end{tabular}

boundary layer and depends not only on the inner roughness $z_{0}$, but also on turbulence-enhanced momentum exchange across the wave boundary layer and damping of turbulent exchange by stratification. The PCADP provided velocity profiles in a series of 0.1 -m bins between $\sim 0.16$ and $\sim 0.76$ mab, making it possible to calculate current shear velocity $u_{*}$ and apparent bottom roughness $z_{0 a}$ by assuming that the burst-mean speed $|U|$ follows a logarithmic profile:

$|U|(z)=\frac{u_{*}}{\kappa} \ln \left(z / z_{0 a}\right)$ where $\kappa$ is the von Kármán constant $(\sim 0.41)$, and $z$ the elevation above the bed. We used the assumptions and least-squares method described in Sherwood et al. (2006b) for PCADP bins centered between 0.16 and 0.76 mab. Time series of measured and modeled shear velocities are shown in Fig. $3 c$, and are correlated with $r^{2}=0.32$.

The apparent bottom roughness estimated from the PCADP profiles is low (median value of $1.3 \times 10^{-5} \mathrm{~m}$ ) relative to values reported for other shelf environments: for example, Sternberg (1967) reported a mean of $6.6 \times 10^{-4} \mathrm{~m}$ in several tidal channels, Schaaff et al. (2006) calculated an apparent roughness of $10^{-4} \mathrm{~m}$ 

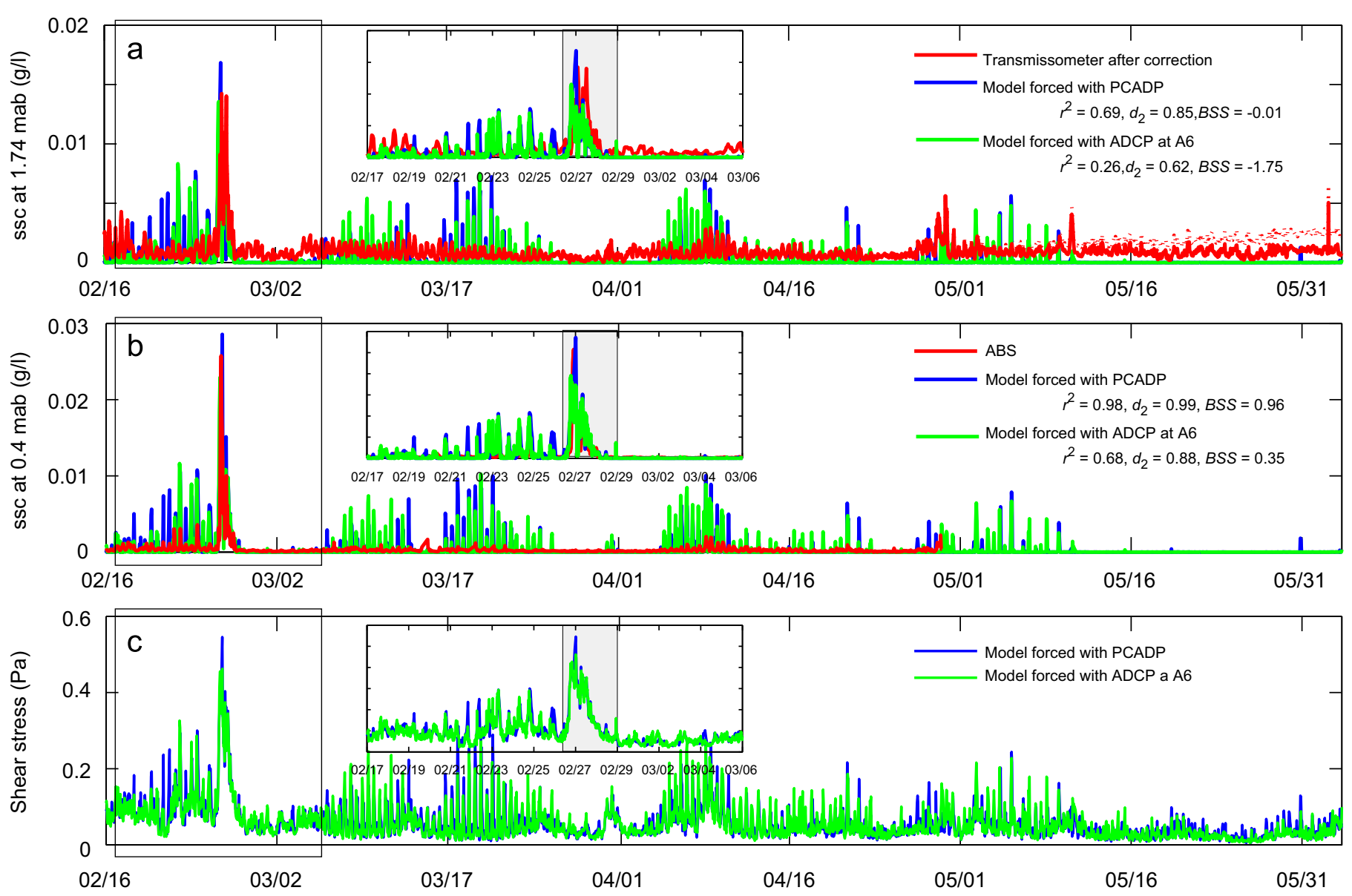

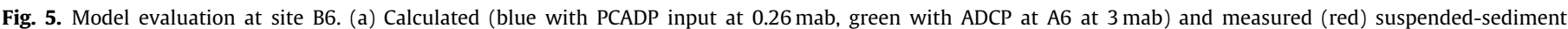

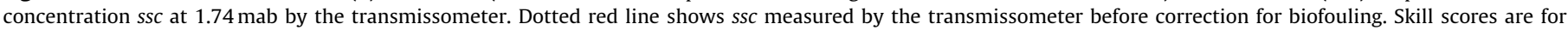

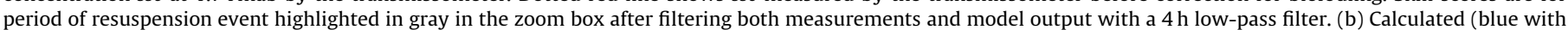

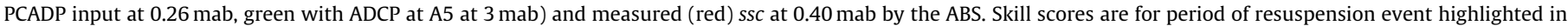

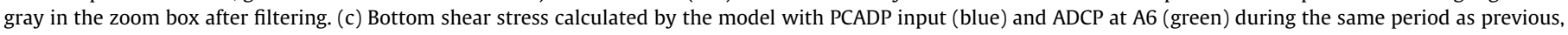
from February to June 2004 at site B6. (For interpretation of the references to color in this figure legend, the reader is referred to the web version of this article.)

in the Gulf of Fos (Mediterranean Sea), Wright et al. (1999, their Fig. 5b) reported a value of about $5 \times 10^{-3} \mathrm{~m}$ on the Eel River shelf, and Lacy et al. (2005) measured $z_{0 a}$ ranging from $10^{-4}$ to $10^{-1} \mathrm{~m}$ on the inner shelf near Grays Harbor, Washington using the same instruments and methodology applied here. This is consistent with observations, which suggest that the PV shelf is smooth at scales of centimeters to meters. Side-scan sonar images of the mid-shelf region show that the bottom is smooth with low acoustic reflectivity (SAIC, 2005a). Photos of the seafloor on the Palos Verdes shelf (Edwards and Chezar, 1994; SAIC, 2005a) show ripples and vestiges of ripples in depths less than $50 \mathrm{~m}$. At depths greater than $50 \mathrm{~m}$, the bottom is soft and dominated by burrows and pits, with frequent mounds and tracks. This smooth, soft seafloor dominated by biological activity is consistent with the observed low hydrodynamic roughness.

We chose the required value of inner roughness by running the model forced with B6 PCADP data at 0.26 mab with a range of $z_{0}$ and comparing the modeled $u_{*}$ with measured values. Best agreement between modeled values of $u_{*}$ and the subset of measured profiles that had $|U|>0.05 \mathrm{~ms}^{-1}$ and $r^{2} \geq 0.99$ were obtained with a bottom roughness of $z_{0}=9 \times 10^{-5} \mathrm{~m}$. Our results are not particularly sensitive to uncertainty in $z_{0}$ (Section 5 ).

\subsubsection{Sediment characteristics}

The sediment size classes and fractions used in the model were based on gentle wet-sieving of naturally aggregated surface sediment samples from box cores and gravity cores collected in 1992 (dots in Fig. 1; Drake, 1994; Drake et al., 2002). Critical shear stress for particles in each of the modeled sediment classes was calculated according to Wiberg and Smith (1987) and settling velocities for particles larger than $63 \mu \mathrm{m}$ were calculated according to the empirical formula of Dietrich (1982). Settling velocities for the finest particle sizes (less than $63 \mu \mathrm{m}$ ) were adjusted within the range for each size class (Table 2) to best fit the optical suspended sediment observations.

After evaluating many model runs, we assigned different sediment behaviors to our two field sites. We modeled sediment at site B3 (where 65\% of the particles were finer than $63 \mu \mathrm{m}$, with $25 \%$ in the clay fraction) as cohesive (muddy) material, and sediment at site B6 (where only $41 \%$ of particles were less than $63 \mu \mathrm{m}$, with only $13 \%$ in the clay fraction) as non-cohesive (sandy) material (Table 2).

Erodibility of cohesive sediment was determined experimentally from field measurements made in 2004. Cores (internal diameter of $10.7 \mathrm{~cm}$ ) with nearly undisturbed sediment-water interfaces were obtained using a hydraulically damped slow gravity corer (Bothner et al., 1997; Bothner et al., 1998) at ten locations (crosses in Fig. 1). The mass of sediment eroded from the top of each core was measured as a function of applied shear stress using an erosion chamber (Gust and Muller, 1997). Bottom shear stresses increasing from 0.08 to $0.4 \mathrm{~Pa}$, in increments of $0.08 \mathrm{~Pa}$, were applied in the erosion chamber, and the mass of 
Table 2

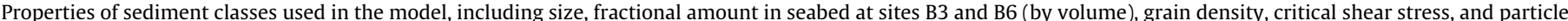
settling velocity.

\begin{tabular}{|c|c|c|c|c|c|c|}
\hline Size $(\phi)$ & Size $(\mu \mathrm{m})$ & Fraction at B3 (\%) & Fraction at B6 (\%) & $\rho_{s}\left(\mathrm{~kg} \mathrm{~m}^{-3}\right)$ & $\tau_{c r}(\mathrm{~Pa})$ & $w_{s}\left(\mathrm{~cm} \mathrm{~s}^{-1}\right)$ \\
\hline 7.8 & 6 & 25 & 13 & 2650 & 0.09 & 0.01 \\
\hline 5 & 31 & 26 & 10 & 2650 & 0.09 & 0.03 \\
\hline 4.3 & 51 & 14 & 18 & 2650 & 0.09 & 0.12 \\
\hline 3.5 & 88 & 27 & 56 & 2650 & 0.11 & 0.4 \\
\hline 2.5 & 177 & 5 & 2 & 1600 & 0.04 & 0.5 \\
\hline 1 & 500 & 3 & 1 & 1550 & 0.03 & 2.4 \\
\hline
\end{tabular}

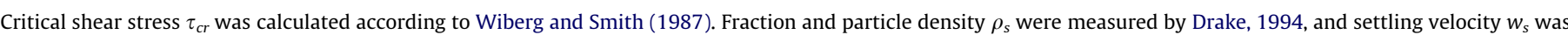
calculated according to Dietrich (1982) for particles $>63 \mu \mathrm{m}$ and chosen for finer particles to best fit the model with observed ssc.

sediment eroded was determined by collecting water samples and determining the amount of suspended material retained on $0.7-\mu \mathrm{m}$ filters. The erodibility of each sample was summarized with a linear regression on a log-log basis of the cumulative mass eroded from the surface of the core $\left(M\right.$, units of $\left.\mathrm{kg} / \mathrm{m}^{2}\right)$ as a function of the applied shear stress $\tau_{s f m}$ (units of Pa; Murray and Chien, 2006):

$\ln (M)=$ slope $\times \ln \left(\tau_{s f m}\right)+$ offset

The slope and the offset were used to characterize sediment erodibility in the model by determining the amount of material available for erosion at any applied shear stress. The coefficients (slope and offset) required to calculate the cumulated eroded mass in Eq. (3) were taken from erosion-chamber measurements closest to site B3 (NW54) and are $1.17 \ln \left(\mathrm{kg} \mathrm{m}^{-2}\right) / \ln (\mathrm{Pa})$ and $0.09 \ln \left(\mathrm{kg} \mathrm{m}^{-2}\right)$, respectively.

Erodibility of non-cohesive sediment was determined using the Harris and Wiberg (1997) calculation of the surface active layer of available sediment in the bed, modified to calculate the cumulative mass eroded $M$ (units of $\mathrm{kg} \mathrm{m}^{-2}$ )

$M=\rho_{s} c_{b}\left[k_{1}\left(\tau_{s f m}-\tau_{c r}\right)+k_{2} d_{50}\right]$

where $\rho_{s}$ is the bed sediment particle density in $\mathrm{kg} \mathrm{m}^{-3}, c_{b}$ the bed sediment concentration (1-porosity), $d_{50}$ the median grain size in $\mathrm{m}$, and $k_{1}$ and $k_{2}$ coefficients with values of $0.001 \mathrm{~m}^{2} \mathrm{~s}^{2}$ $\mathrm{kg}^{-1}$ and 0.1 , respectively, chosen along with a resuspension coefficient (Smith and McLean, 1977) of $\gamma_{0}=0.0002$ to provide the best match with the $\mathrm{ABS}$ and transmissometer observations. Wiberg and Harris (2002) used $k_{1}=0.006 \mathrm{~m}^{2} \mathrm{~s}^{2} \mathrm{~kg}^{-1}$ and $k_{2}=6$ with a resuspension coefficient $\gamma_{0}=0.002$ at site B3 and at muddy sites on the Eel River shelf and Russian River shelf in Northern California (Harris and Wiberg, 1997) but, with their parameters, our model overestimated suspended-sediment observations by a factor of five. The amount of material available for erosion according to Eq. (4) with our parameters is only slightly greater than the amount predicted by Eq. (3) at stresses measured in the erosion chamber. Model results are very sensitive to uncertainties in these parameterizations (Section 5) and we consider this in our conclusions.

The sediment classes used in the model (Table 2) were from USGS core 120B1 near site B6 and 147B3 near site B3 in 1992 (Drake, 1994). We used a resuspension coefficient $\left(2 \times 10^{-4}\right)$ that falls in the range $1.5 \times 10^{-5}-3 \times 10^{-4}$ calculated by Drake and Cacchione (1989) for ten erosion events on the northern California shelf.

\subsection{Results}

The 1DV model produced values of bottom shear stress and profiles of current velocity and suspended-sediment. We calculated modeled shear velocity $u^{*}{ }_{c}$ using $\log$ fits to model output at the same elevation as the PCADP measurements at site B6 for comparison with these data (Fig. 3c).

\subsubsection{Suspended-sediment concentrations}

We compared the modeled suspended-sediment concentration (ssc) with the estimates of ssc from the transmissometers and ABS after removing minimum background values from the measurements (Figs. 4 and 5). Modeled ssc was low compared to transmissometer measurements during some periods (for example, beginning of March at site B3 and beginning and end of March at site B6). Attempts to increase modeled concentration during these events led to overprediction of ssc for other times when bottom stress was elevated but measurements showed no evidence of resuspension. Modeled ssc was sometimes too high compared to ABS measurements (for example, in the beginning of April at site B3 and near the end of March and mid-April at site B6). The difference might be explained by the relative sensitivity of the two instruments to grain size: the transmissometer is more sensitive to fine sediment and ABS is more sensitive to coarse sediment. There were also observations of elevated ssc at site B6 that did not correspond to elevated bottom stress (e.g., the end of April), and we assume these indicated either advection of ssc resuspended elsewhere to the measurement site or temporal changes in bed erodibility. This phenomenon was not observed at site B3. The model clearly captures the only significant resuspension event during the measurement period at both sites (shaded region in zoom boxes in Figs. 4 and 5). The correlation coefficient $r^{2}$ between modeled ssc and measurements (after filtering both with a $4 \mathrm{~h}$ low-pass filter) at site B3 (B6) was 0.74 (0.69) for transmissometer data, and $0.32(0.98)$ for ABS data. The corresponding skill scores were $d_{2}=0.92(0.85)$ and $0.68(0.99)$; and $B S S=0.62(-0.01)$ and $-1.23(0.96)$ (see Section 5.1 for a definition of the skill indices).

We also evaluated model skill for simulations forced with nearby LACSD ADCP measurements made $3 \mathrm{mab}$, as this is how we applied the model for long-term estimates (Section 4). After filtering both measurements and model output with a $4 \mathrm{~h}$ lowpass filter, modeled ssc forced with data from LACSD mooring A3 (near our site B3) and A6 (near our site B6) agreed well with observations (site B3: $r^{2}=0.60$ and $0.86 ; d_{2}=0.80$ and 0.95 ; and $B S S=0.26$ and 0.79 , Figs. $4 \mathrm{a}$ and $\mathrm{b}$ in green; site B6: $r^{2}=0.26$ and $0.68 ; d_{2}=0.62$ and 0.88 ; and $B S S=-1.75$ and 0.35 , Figs. $5 \mathrm{a}$ and $\mathrm{b}$ in green). Correlation forced through zero between observed ssc and model results gives fair agreement $\left(\mathrm{B} 3: r^{2}=0.71\right.$ and 0.52 ; B6: $r^{2}=0.32$ and 0.74; Fig. 6).

\subsubsection{Flow orientation}

Modeled transport direction was significantly influenced by the mean flow selected for forcing, because there were large ( $\sim 50^{\circ}$-differences) in flow orientation in the bottom boundary layer. Two instruments with separate compasses at site B6 (ADV at $0.6 \mathrm{mab}$ and PCADP from 0.16 to $0.86 \mathrm{mab}$ ) indicated that 
transport in the bottom meter was almost due west (toward $266^{\circ}$; Fig. 7). However, measurements from the USGS ADCP mounted on the same bottom tripod indicated transport at 13 mab toward the northwest (319 ; Fig. 7). These are consistent with measurements made $12 \mathrm{mab}$ for the same period at LACSD site A6 (depth $=65 \mathrm{~m})$, located $\sim 1.7 \mathrm{~km}$ SSE of B6 (depth $=58 \mathrm{~m}$; Fig. 1 ). The LACSD data exhibited more rotation ( $39^{\circ}$ between 12 and $6 \mathrm{mab}$ ) than the USGS ADCP ( $29^{\circ}$ between 13 and $\left.7 \mathrm{mab}\right)$. The $1 \mathrm{DV}$ model produces a

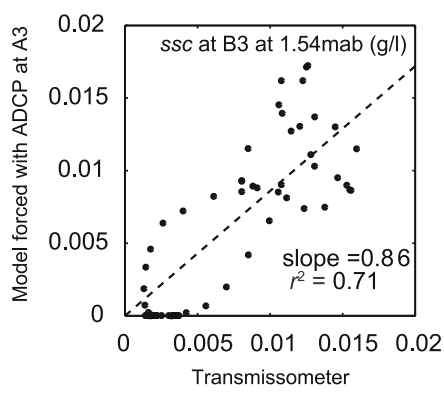

C

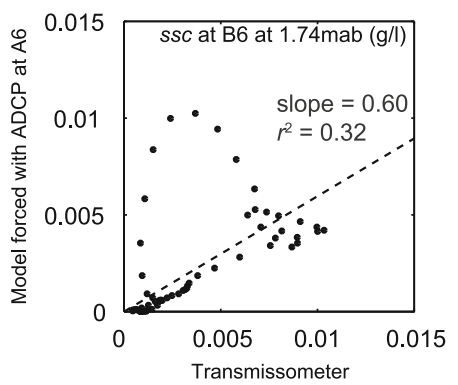

b

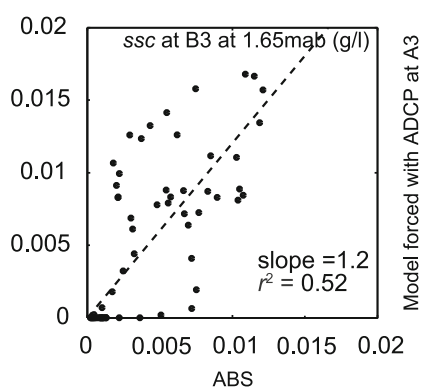

d

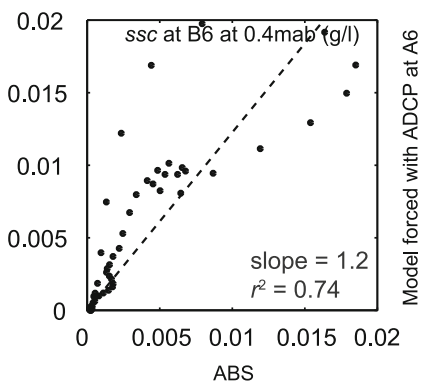

Fig. 6. Correlations forced through zero between observed data and model results after filtering both with a $4 \mathrm{~h}$ low-pass filter. (a) At B3, between transmissometer at $1.54 \mathrm{mab}$ and the model forced with ADCP data at A3. (b) At B3, between ABS at 1.65 mab and the model forced with ADCP data at A3. (c) At B6, between transmissometer at 1.74 mab and model forced with ADCP data at A6. (d) At B6, between ABS at 0.4 mab and model forced with ADCP data at A6. Dashed line in each subplot is the linear regression forced through zero. The slope and correlation coefficient squared are indicated. rotation of only $2.8^{\circ}$ between 13 and 7 mab. The analytical solution for an idealized Ekman layer with vertically uniform eddy viscosity (e.g., Pedlosky, 1987, Eq. (4.3.20)) produces a rotation of about $8^{\circ}$ between 13 and 7 mab, assuming a typical eddy viscosity of $10^{-2} \mathrm{~m}^{2} \mathrm{~s}^{-1}$. A maximum plausible rotation of $12.5^{\circ}$ can be obtained using a large eddy viscosity of $3.8 \times 10^{-2} \mathrm{~m}^{2} \mathrm{~s}^{-1}$. These calculations suggest that the large rotation observed between the ADCPs and the near-bottom instruments at site B6 was not caused by simple barotropic Ekman dynamics, and the duplication among instruments at both elevations suggests it was not a compass issue. The large rotations are consistent with the effects of thermohaline stratification (not included in the model) which can compress the Ekman layer and increase rotation near the seabed. Another possibility is that internal bores have influenced the mean-flow statistics, and we hope to investigate this in future work.

\section{Application of the $1 D V$ model forced by the LACSD ADCP data}

\subsection{Data}

LACSD engineers deployed upward-looking acoustic Doppler current profilers (ADCPs) at 13 sites on the 35- and 65-m isobaths on the PV and San Pedro shelves (Fig. 1; Table 3) for various periods between November 2000 and May 2006. The total record length ranged from 1286 to 1931 days (Table 3). The instruments were SonTek, Inc. $500 \mathrm{kHz}$ 4-beam (Janus configuration) ADCPs, deployed in trawl-resistant bottom mounts with transducers located approximately 2 mab. Profiles were recorded in 3-m bins, and we used data from the first cell, centered 3 mab. Threeminute averages were recorded every $15 \mathrm{~min}$ and converted to northward and eastward (magnetic) components in situ using the ADCP compass and instrument firmware. Post-processing of these data was performed by LACSD and included rotation to geographic coordinates using the local magnetic declination $\left(13.6^{\circ} \mathrm{E}\right)$, reformatting, and quality assessment using screening criteria based on velocities, signal strength, signal-to-noise ratio, and standard deviation of current speed (LACSD, 2006). No data

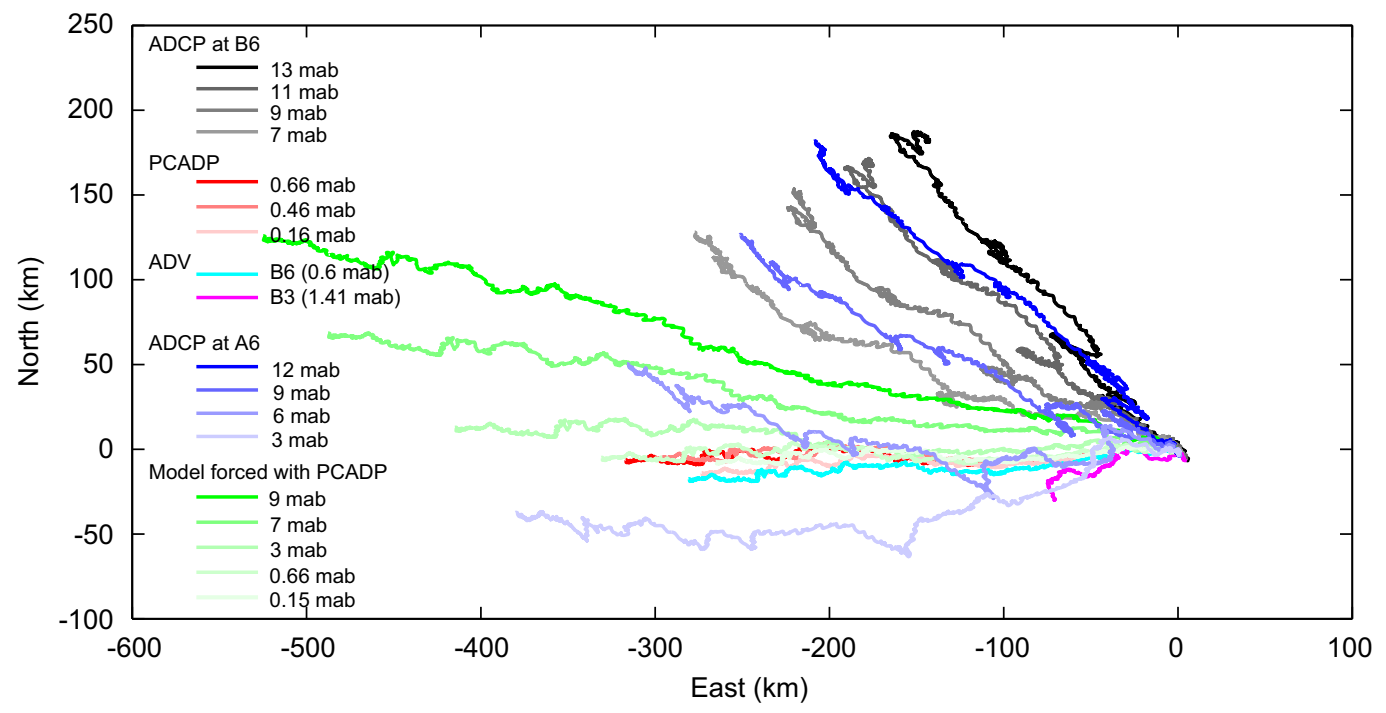

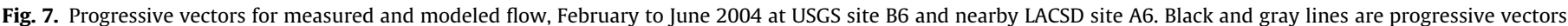

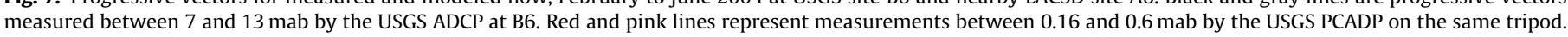

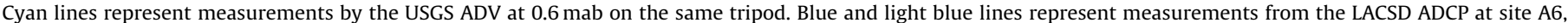
located approximately $1.7 \mathrm{~km}$ SSE from B6. Green lines represent modeled flow at various elevations, forced by PCADP measurements at 0.16 mab. 
Table 3

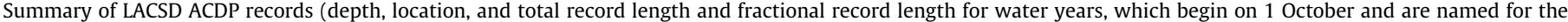
year in which they end).

\begin{tabular}{|c|c|c|c|c|c|c|c|c|c|}
\hline \multirow[t]{2}{*}{ Station ID } & \multirow[t]{2}{*}{ Depth (m) } & \multirow[t]{2}{*}{ Location } & \multirow[t]{2}{*}{ Total record length (days) } & \multicolumn{6}{|c|}{ Record length (fraction of water year) } \\
\hline & & & & 2001 & 2002 & 2003 & 2004 & 2005 & 2006 \\
\hline A1 & 65 & $33^{\circ} 45^{\prime} 55.08^{\prime \prime} \mathrm{N} / 118^{\circ} 27^{\prime} 0.36^{\prime \prime} \mathrm{W}$ & 1889 & 0.86 & 1.00 & 0.97 & 0.77 & 1.00 & 0.57 \\
\hline $\mathrm{A} 2$ & 65 & $33^{\circ} 43^{\prime} 58.44^{\prime \prime} \mathrm{N} / 118^{\circ} 24^{\prime} 57.96^{\prime \prime} \mathrm{W}$ & 1775 & 0.89 & 1.00 & 1.00 & 0.62 & 0.77 & 0.57 \\
\hline A3 & 65 & $33^{\circ} 42^{\prime} 59.40^{\prime \prime} \mathrm{N} / 118^{\circ} 22^{\prime} 15.24^{\prime \prime} \mathrm{W}$ & 1764 & 0.86 & 0.99 & 0.97 & 0.77 & 1.00 & 0.24 \\
\hline A5 & 65 & $33^{\circ} 41^{\prime} 45.60^{\prime \prime} \mathrm{N} / 118^{\circ} 20^{\prime} 0.96^{\prime \prime} \mathrm{W}$ & 1861 & 0.78 & 1.00 & 0.97 & 0.78 & 1.00 & 0.57 \\
\hline A6 & 65 & $33^{\circ} 40^{\prime} 11.28^{\prime \prime} \mathrm{N} / 118^{\circ} 17^{\prime} 58.20^{\prime \prime} \mathrm{W}$ & 1850 & 0.74 & 1.00 & 0.98 & 0.53 & 1.00 & 0.57 \\
\hline A8 & 65 & $33^{\circ} 37^{\prime} 32.16^{\prime \prime} \mathrm{N} / 118^{\circ} 15^{\prime} 41.40^{\prime \prime} \mathrm{W}$ & 1804 & 0.90 & 1.00 & 0.96 & 0.75 & 1.00 & 0.32 \\
\hline $\mathrm{AA}$ & 65 & $33^{\circ} 34^{\prime} 55.92^{\prime \prime} \mathrm{N} / 118^{\circ} 12^{\prime} 17.64^{\prime \prime} \mathrm{W}$ & 1286 & 0 & 0.21 & 0.96 & 0.78 & 1.00 & 0.56 \\
\hline AC & 65 & $33^{\circ} 34^{\prime} 57.72^{\prime \prime} \mathrm{N} / 118^{\circ} 8^{\prime} 29.04^{\prime \prime} \mathrm{W}$ & 1364 & 0 & 0.45 & 1.00 & 0.99 & 1.00 & 0.29 \\
\hline A4 & 35 & $33^{\circ} 43^{\prime} 23.88^{\prime \prime} \mathrm{N} / 118^{\circ} 22^{\prime} 1.20^{\prime \prime} \mathrm{W}$ & 1721 & 0.82 & 1.00 & 0.97 & 0.61 & 0.94 & 0.37 \\
\hline A7 & 35 & $33^{\circ} 41^{\prime} 27.60^{\prime \prime} \mathrm{N} / 118^{\circ} 17^{\prime} 31.92^{\prime \prime} \mathrm{W}$ & 1847 & 0.75 & 1.00 & 0.96 & 0.78 & 1.00 & 0.57 \\
\hline A9 & 35 & $33^{\circ} 39^{\prime} 58.68^{\prime \prime} \mathrm{N} / 118^{\circ} 15^{\prime} 56.16^{\prime \prime} \mathrm{W}$ & 1931 & 0.82 & 1.00 & 1.00 & 0.90 & 1.00 & 0.57 \\
\hline $\mathrm{AB}$ & 35 & $33^{\circ} 38^{\prime} 1.32^{\prime \prime} \mathrm{N} / 118^{\circ} 12^{\prime} 23.76^{\prime \prime} \mathrm{W}$ & 1426 & 0 & 0.34 & 1.00 & 1.00 & 1.00 & 0.56 \\
\hline $\mathrm{AD}$ & 35 & $33^{\circ} 37^{\prime} 58.80^{\prime \prime} \mathrm{N} / 118^{\circ} 8^{\prime} 54.24^{\prime \prime} \mathrm{W}$ & 1365 & 0 & 0.59 & 1.00 & 0.89 & 0.69 & 0.56 \\
\hline
\end{tabular}

were removed or replaced. Later in this paper, we evaluate transport for each of the six water years (which extend from October 1 to September 30 and are named for the year in which they end). The fractions of each water year for which data are available are listed in Table 3.

\subsection{Model input}

\subsubsection{Currents and wave-orbital velocity}

We used the LACSD current time series at 3 mab as input to sediment-transport calculations, and because wave measurements were not available at the ADCP sites, we calculated nearbottom orbital velocities $u_{b(\text { buoy }}$ from wave spectra recorded at a nearby buoy. Directional wave spectra and statistics were available from Coastal Data and Information Processing (CDIP) buoy 46222, a directional Waverider buoy moored in water $457 \mathrm{~m}$ deep in the San Pedro Channel $\left(33.62^{\circ} \mathrm{N}, 118.32^{\circ} \mathrm{W}\right)$ approximately $9 \mathrm{~km}$ south of the PV shelf (Fig. 1). Directional wave spectra and statistics have been recorded by the buoy since February 21, 1998. Wave-orbital velocities calculated from these spectra assuming linear wave theory (Wiberg and Sherwood, 2008) were generally higher than ADV measurements of $u_{b r}$ made at sites B3 and B6 on the PV shelf, so we adjusted for refraction and shoaling. The expected orbital velocities at site $\mathrm{B} 6$ can be inferred from buoy data as $u_{b(\mathrm{~B} 6)}=K_{s} K_{r} u_{b(\text { buoy) }}$, where shoaling coefficient $K_{s}$ depends on the changes in wave celerity with depth (a function of wave period and water depth), and refraction coefficient $K_{r}$ depends on the change in angle of wave approach (Dean and Dalrymple, 1991). The linear fit forced through zero between the orbital velocities measured by the ADV at site B6 and directly calculated from the buoy spectra were well-correlated $\left(r^{2}=0.86\right)$ with a constant $K_{s} K_{r}$ of 0.84 . We used a similar procedure and found that the best-fit value of $K_{s} K_{r}$ at the $35-\mathrm{m}$ sites on the PV shelf was 0.78 . We used these two values to adjust estimates of $u_{b(\text { buoy) }}$ (calculated using appropriate depths) for input to the model at all of the LACSD sites. This is likely to have introduced some error in the model results because wave conditions may have varied among the sites. However, there is evidence that on the PV shelf, wave variability is low along the 65-m isobath between Pt. Fermin and the region offshore of the Portuguese Bend Landslide. Model results (Sherwood and Hibler, 1994) suggested that waves were nearly uniform along the PV shelf and simultaneous measurements of pressure variance recorded by the ADV at site $\mathrm{B} 6$ and a similar instrument at site B3 (Fig. 1) indicated wave-orbital velocities were only a few percent different.
Errors are likely to be greater on the San Pedro shelf, where sites were farther from the buoy and wave-refraction angles differ. Qualitative judgments based on wave heights calculated with the CDIP Southern California wave model (http://cdip.ucsd. edu) suggest that waves were likely to be smaller on the San Pedro shelf, and our input wave-orbital velocities may be biased high at those sites.

\subsubsection{Sediment characteristics}

Sediment size-class distributions and erodibility coefficients were not available from the LACSD ADCP sites, so we used sediment-size distributions from the closest USGS samples (Drake, 1994; Drake et al., 2002) at similar depths (Fig. 1) and erosion-chamber analyses from the closest sampling sites (Table 4). The resulting inferred sediment characteristics are well constrained on the PV shelf but, because there are fewer data available for the San Pedro shelf, the sediment properties are less certain. They generally agree with regional maps of bottom sediment on the Southern California shelf, which indicate silty clay with $<20 \%$ clay (Emery, 1960; Dailey et al., 1993). We used the same class characteristics (density, settling velocity, and critical shear stress) that were used for comparison with the 2004 bbl measurements (Table 2) with class distributions shown in Table 4, and the same uniform resuspension coefficient and bottom roughness. We modeled sediment at sites A3 and A4 (where more than $50 \%$ of the particles were finer than $63 \mu \mathrm{m}$ ) as cohesive (muddy) material (Eq. (3)), and sediment at other sites (where less than $50 \%$ of particles were finer than $63 \mu \mathrm{m}$ ) as noncohesive (sandy) material (Eq. (4)).

\subsection{Results}

This section describes the 1DV model results forced with the LACSD ADCP current-meter data, the CDIP buoy wave data, and our best estimates of local sediment characteristics. We discuss modeled bottom stress, sediment transport rate and horizontal gradients in transport rate, and seasonal variations in transport. We focus more closely on results from the $65-\mathrm{m}$ sites on the PV shelf, because these are the sites where we are most concerned with the fate of the effluent-affected deposit, and for which we have the least uncertainty in our wave and sediment data.

\subsubsection{Bottom stress}

Time series of modeled current and wave bottom shear stress at the thirteen sites (Fig. 8) confirm previous results (Wiberg and 
Table 4

Sediment characteristics used in the model at each LACSD ADCP site.

\begin{tabular}{|c|c|c|c|c|c|c|c|c|c|c|c|c|c|c|}
\hline \multirow[t]{2}{*}{ Depth (m) } & \multirow[t]{2}{*}{ Station } & \multirow{2}{*}{$\begin{array}{l}\text { Eq./erosion-chamber } \\
\text { station when relevant }\end{array}$} & \multirow[t]{2}{*}{$k_{1} / k_{2}$ or slope/offset } & \multirow[t]{2}{*}{ USGS core } & \multicolumn{6}{|c|}{ Size class $(\phi)$} & \multirow[t]{2}{*}{ Mean size $(\phi)$} & \multirow[t]{2}{*}{$w_{s}(\mathrm{~mm} / \mathrm{s})$} & \multirow[t]{2}{*}{$\rho_{s}\left(\mathrm{~kg} / \mathrm{m}^{3}\right)$} & \multirow[t]{2}{*}{$\tau_{c r}(\mathrm{~Pa})$} \\
\hline & & & & & 7.8 & 5 & 4.3 & 3.5 & 2.5 & 1 & & & & \\
\hline \multirow[t]{8}{*}{65} & $\mathrm{~A} 1$ & 4 & $0.01 / 0.1$ & 160B1 & 14 & 13 & 19 & 48 & 4 & 2 & 4.36 & 0.29 & 2586 & 0.10 \\
\hline & $\mathrm{A} 2$ & 4 & $0.01 / 0.1$ & 107B1 & 17 & 15 & 15 & 41 & 8 & 4 & 4.40 & 0.32 & 2522 & 0.09 \\
\hline & A3 & 3/NW39 & $1.93 / 0.05$ & 116B1 & 30 & 22 & 20 & 24 & 2 & 2 & 5.21 & 0.19 & 2607 & 0.09 \\
\hline & A5 & 4 & $0.01 / 0.1$ & 154B1 & 21 & 18 & 20 & 28 & 9 & 4 & 4.64 & 0.28 & 2512 & 0.09 \\
\hline & A6 & 4 & $0.01 / 0.1$ & 152B1 & 6 & 3 & 5 & 72 & 13 & 1 & 3.69 & 0.38 & 2503 & 0.09 \\
\hline & A8 & 4 & $0.01 / 0.1$ & 154B1 & 6 & 3 & 5 & 72 & 13 & 1 & 3.69 & 0.38 & 2503 & 0.09 \\
\hline & AA & 4 & $0.01 / 0.1$ & 152B1 & 6 & 3 & 5 & 72 & 13 & 1 & 3.69 & 0.38 & 2503 & 0.09 \\
\hline & AC & 4 & $0.01 / 0.1$ & $152 \mathrm{~B} 1$ & 6 & 3 & 5 & 72 & 13 & 1 & 3.69 & 0.38 & 2503 & 0.09 \\
\hline \multirow[t]{5}{*}{35} & A4 & 3/OUT27 & $2.15 /-0.08$ & 111B1 & 22 & 17 & 17 & 38 & 5 & 1 & 4.76 & 0.23 & 2587 & 0.10 \\
\hline & A7 & 4 & $0.01 / 0.1$ & 119B2 & 14 & 16 & 17 & 48 & 4 & 1 & 4.41 & 0.26 & 2597 & 0.10 \\
\hline & A9 & 4 & $0.01 / 0.1$ & 119B2 & 14 & 16 & 17 & 48 & 4 & 1 & 4.41 & 0.26 & 2597 & 0.10 \\
\hline & $\mathrm{AB}$ & 4 & $0.01 / 0.1$ & 119B2 & 14 & 16 & 17 & 48 & 4 & 1 & 4.41 & 0.26 & 2597 & 0.10 \\
\hline & $A D$ & 4 & $0.01 / 0.1$ & 119B2 & 14 & 16 & 17 & 48 & 4 & 1 & 4.41 & 0.26 & 2597 & 0.10 \\
\hline
\end{tabular}

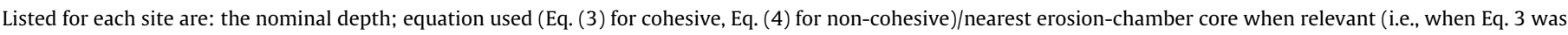

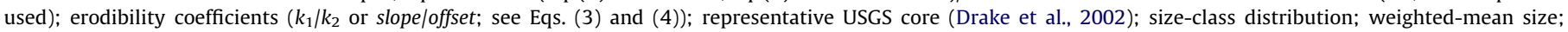
weighted-mean settling velocity; and weighted-mean critical shear stress calculated from size-class distribution.

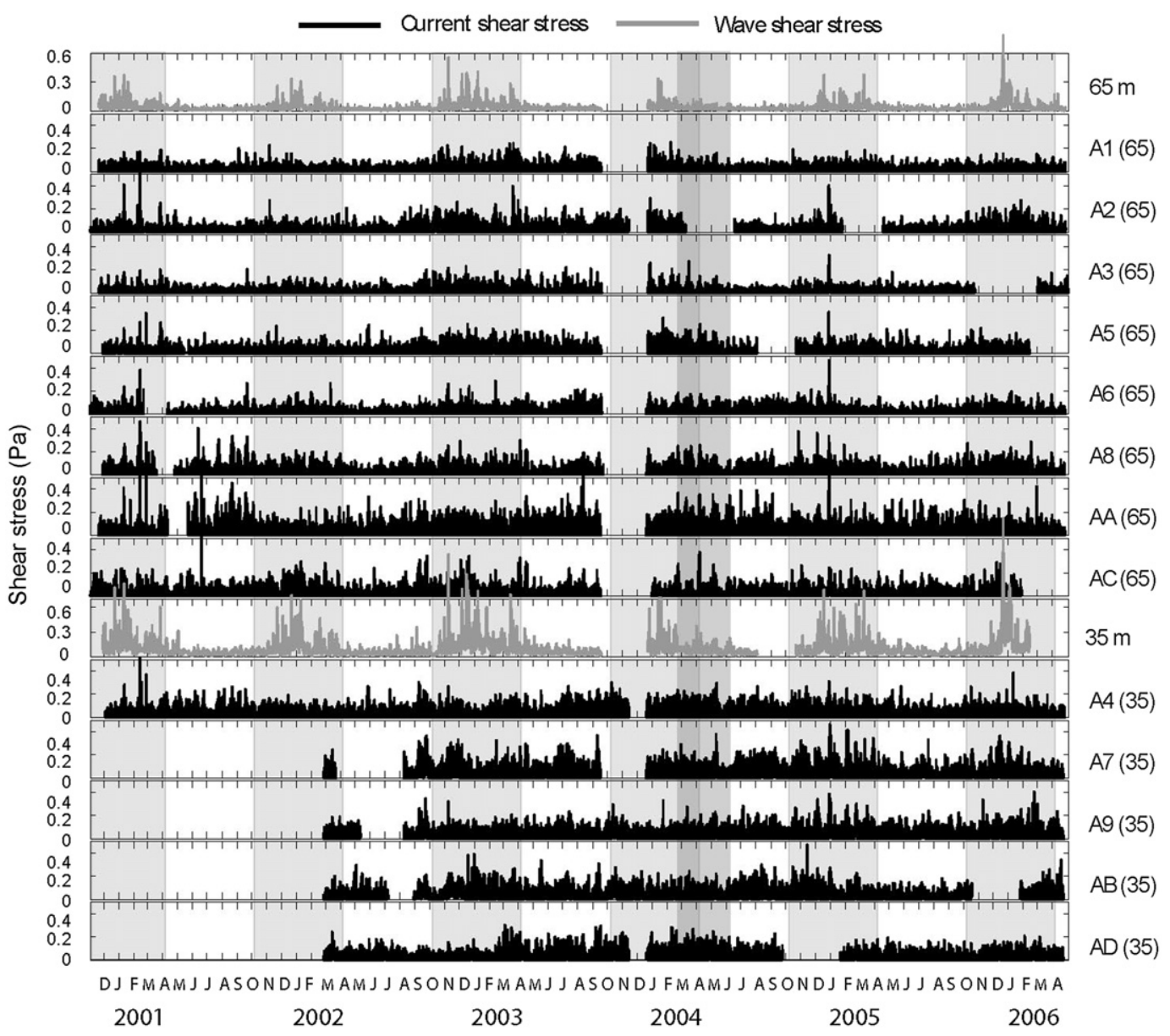

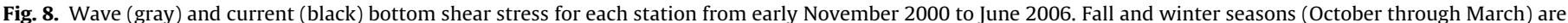

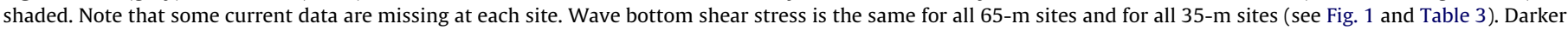
shading indicates the period with bbl measurement used to calibrate the model.

Harris, 2002; Xu and Noble, 2009) that enhanced stress associated with wave events occurred in winter (from October to March), and the mean and principal components of currents 3 mab (Fig. 9) confirm that mean flow was mostly alongshore toward the northwest (Noble et al., 2002; Noble et al., 2009). The cumulative distributions of wave-current combined bottom shear stresses calculated by the model (Fig. 10) show that stresses were higher at the $35-\mathrm{m}$ sites because of the higher nearbottom wave-orbital velocities there. Calculations for the $35-\mathrm{m}$ sites indicated that the approximate threshold of resuspension ( $0.09 \mathrm{~Pa}$, calculated from the median of the critical shear stress at $35-\mathrm{m}$ sites) was exceeded $\sim 30 \%-45 \%$ of the time. At the 
65 -m sites, this threshold was exceeded between $5 \%$ and $20 \%$ of the time. On the 65-m sites on the PV shelf, highest stresses were calculated on the southeast end of the PV shelf at site A6, where the 95th percentile bottom stresses were $0.12 \mathrm{~Pa}$ (Fig. 11a). Bottom stresses were slightly lower northwest of the outfalls (A3; 95th percentile $=0.09 \mathrm{~Pa}$, Fig. 11a).

The ratio of bottom stress to critical bed stress provides an indication of sediment mobility; sediment can be expected to move when $\tau_{s f m} / \tau_{c r}$ exceeded one. The 95th percentile of this dimensionless ratio was high in San Pedro shelf and lowest on the PV shelf (Fig. 11b). The shear-stress ratios were substantially higher at all of the 35-m sites.

We used the erodibility coefficients (Table 4 and Eqs. (3) and (4)) to estimate, at each site, the mass of sediment remobilized at the 95th percentile bottom stress (Fig. 11c). This allowed us to compare the combined effects of the stress distribution (Fig. 10) and erodibility, and indicated that more material was likely to be

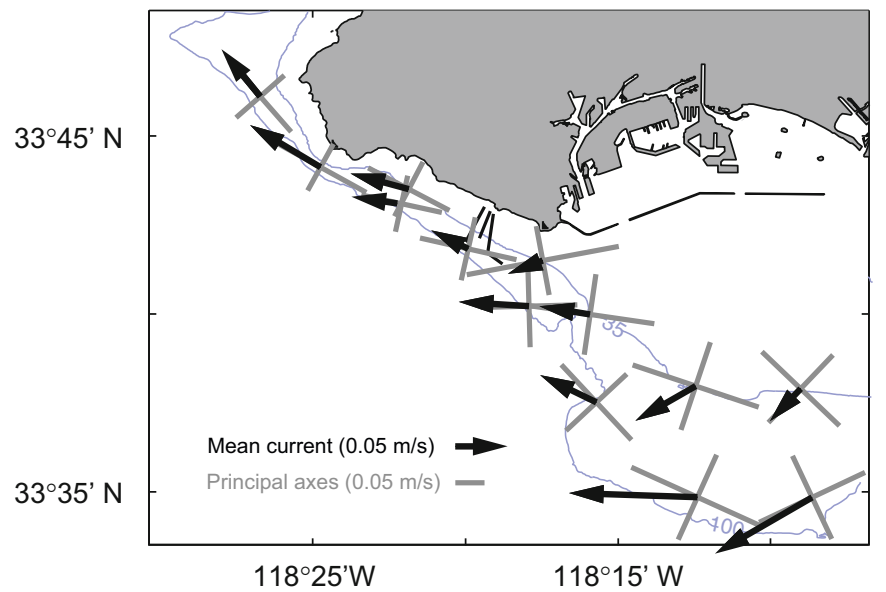

Fig. 9. Mean current velocity and principal axes of variation for LACSD ADCP measurements in the bottom bin ( $3 \mathrm{mab}$ ) for the entire record (Fig. 8 and Table 3 ). remobilized on the San Pedro shelf $\left(0.05 \mathrm{~kg} \mathrm{~m}^{-2}\right.$ at AA) than at either the less mobile region on the southeast end of the PV shelf $\left(0.02 \mathrm{~g} \mathrm{~m}^{-2}\right.$ at A6) or the lower-energy region on the northwest end of the PV shelf $\left(0.01 \mathrm{~g} \mathrm{~m}^{-2}\right.$ at A1). Much more material ( $>0.1 \mathrm{~kg} \mathrm{~m}^{-2}$ ) could be remobilized at the $35-\mathrm{m}$ sites, where near-bottom wave-orbital velocities acted to increase bottom stress. Calculation of the mass of sediment remobilized at a relatively high fixed shear stress of $0.32 \mathrm{~Pa}$ showed more homogeneous distribution, between 0.13 and $0.14 \mathrm{~kg} \mathrm{~m}^{-2}$ on the $65-\mathrm{m}$ sites and between 0.08 and $0.13 \mathrm{~kg} \mathrm{~m}^{-2}$ on the $35-\mathrm{m}$ sites (Fig. 11d).

\subsubsection{Sediment transport and horizontal transport gradients}

Suspended-sediment transport rate $F$ in the water column was calculated from model results at $15 \mathrm{~min}$ intervals for each site by vertical integration from the bed to 10 mab using

$$
\begin{aligned}
& F_{x}=\sum_{z} \operatorname{ssc}(z) u(z) \Delta z \\
& F_{y}=\sum_{z} \operatorname{ssc}(z) v(z) \Delta z \\
& F=\sqrt{F_{x}^{2}+F_{y}^{2}}
\end{aligned}
$$

where $F$ is the magnitude of the total (in $\mathrm{kg} \mathrm{m}^{-1} \mathrm{~s}^{-1}$ ), ssc the suspended-sediment mass concentration (in $\mathrm{kg} \mathrm{m}^{-3}$ ), $u$ and $v$ eastward and northward velocity components (in $\mathrm{ms}^{-1}$ ), and $\Delta z$ the vertical spacing of model profiles (in $\mathrm{m}$ ) calculated at $\sim 350$ logarithmically spaced elevations.

We used the jackknife statistical approach (Emery and Thomson, 2001, p. 301) to estimate the uncertainty in annual sediment-transport rates for each modeled time series. The jackknife method involved calculating $N$ jackknife means (denoted $\bar{x}_{i}$, where $i=1$ to $N$ ) from subsamples of the modeled results, withholding part of the data each time. In our case, we withheld one water year of model results from each jackknife mean, so $N=6$ for the PV sites and 3 or 4 for the San Pedro sites. The mean of

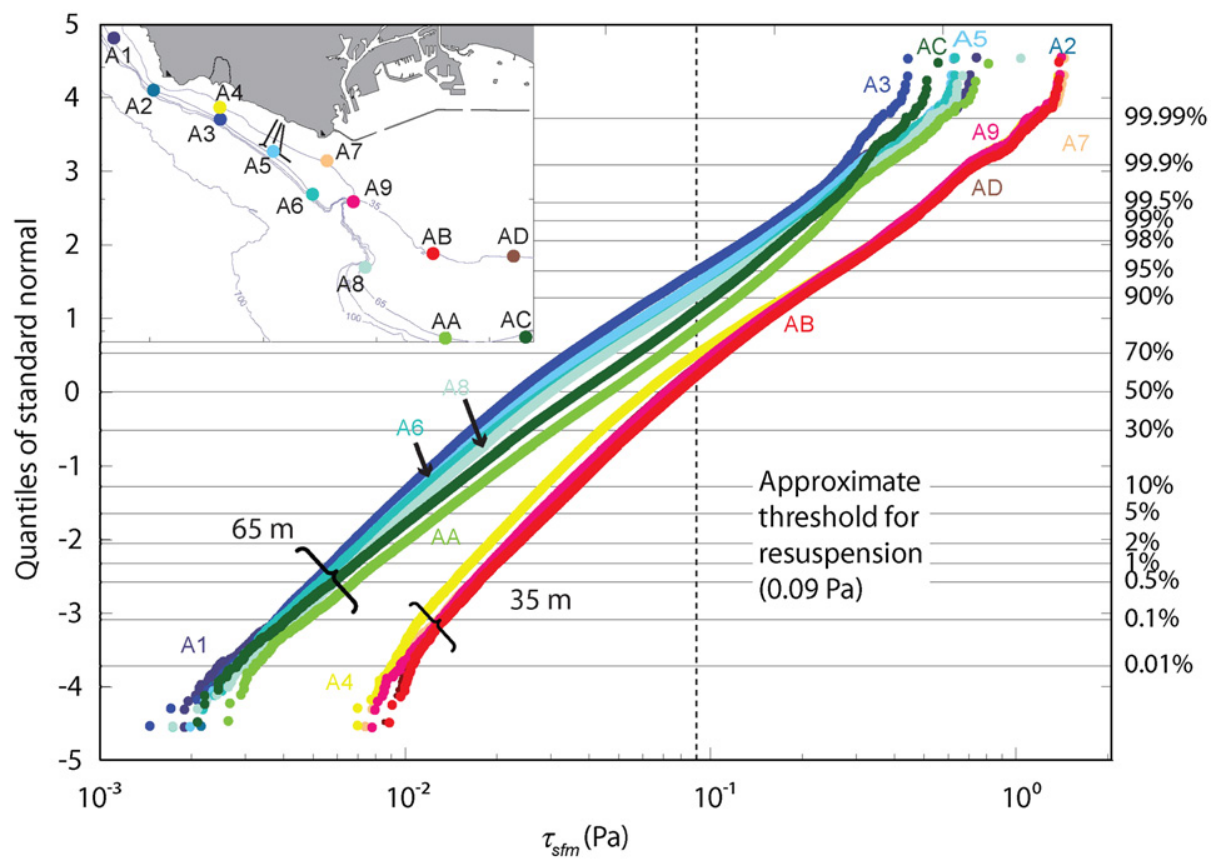

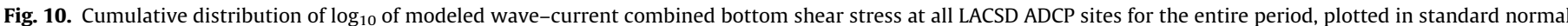

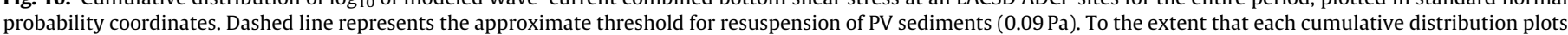

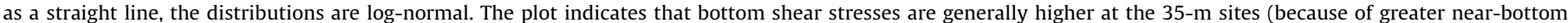
wave motions), and that the threshold for resuspension is exceeded approximately $25 \%$ of the time at site AA, but only about $4 \%$ of the time at site A3. 

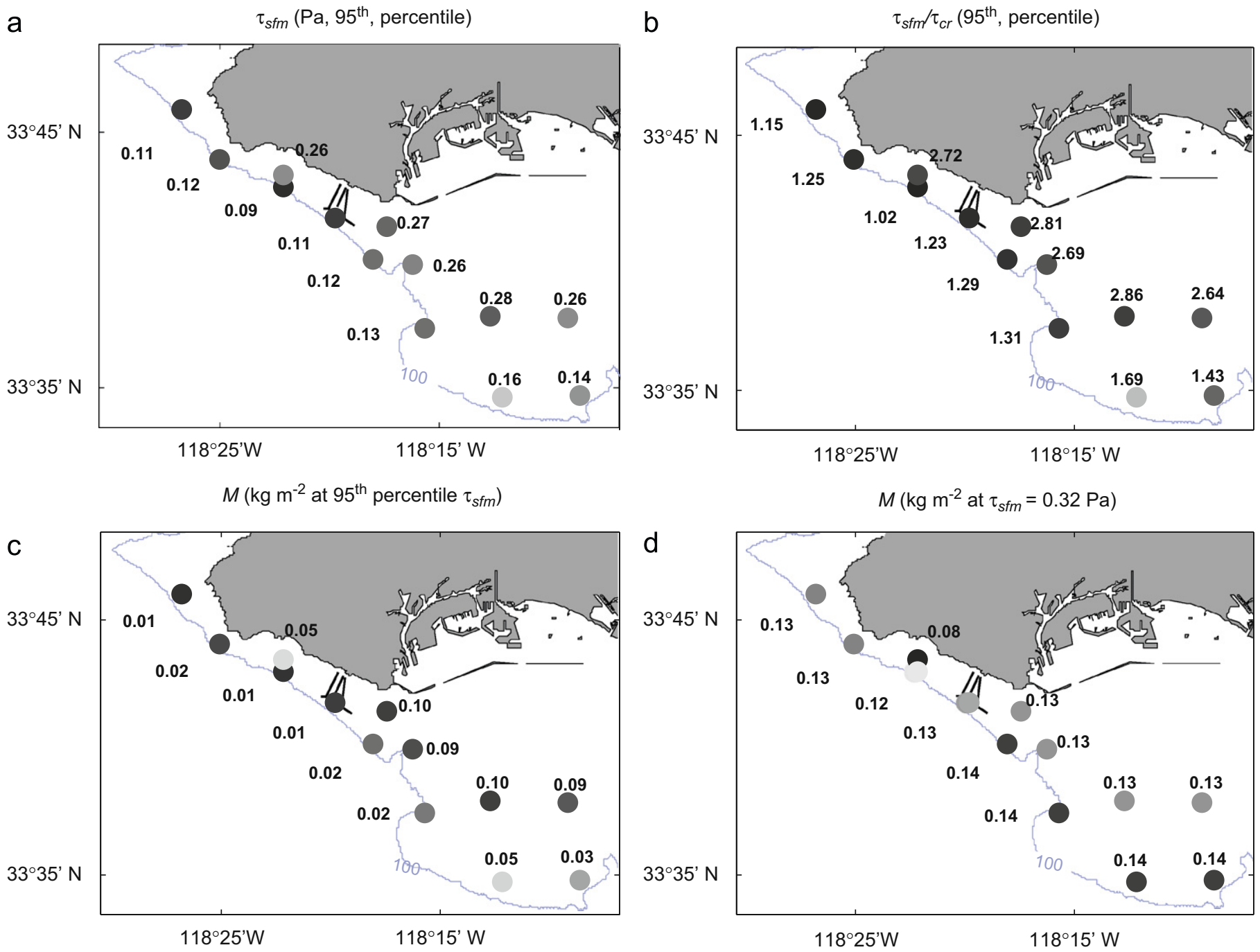

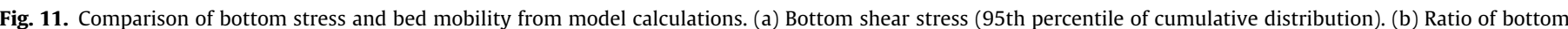

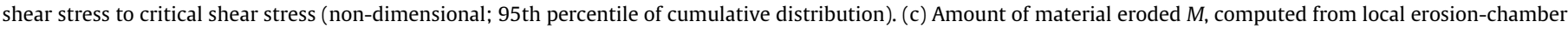
results and using the 95th percentile of bottom stress. (d) Amount of material eroded at bottom stress of 0.32 Pa. Only the 100 -m contour is shown.

these $N$ jackknife means was the same as the mean of the entire model results, and the standard deviation of the $N$ means provided an estimate of the uncertainty of our estimates associated with interannual variability.

Results of the sediment-transport calculations are summarized in Table 5 and black arrows on Fig. 12. The magnitude of the mean transport rates on the PV shelf varied from 0.9 to $4.8 \mathrm{t} \mathrm{m}^{-1} \mathrm{yr}^{-1}$ at the $65-\mathrm{m}$ sites (Table 5 , column 3 ). Rates were higher (6.2$17.2 \mathrm{t} \mathrm{m}^{-1} \mathrm{yr}^{-1}$ ) at the $35-\mathrm{m}$ sites, a consequence of greater waveinduced bed stresses in shallower water (Table 5, column 3 ). The uncertainty about the mean transport rates (associated with interannual variation using the jackknife estimate) was about $50 \%$ (Table 5, column3) but at some sites (A1, AD) was more than $100 \%$. Rates along the $65-\mathrm{m}$ isobath on the Palos Verdes shelf were, from southwest to northwest, 1.1 (A6), 2.2 (A5), 1.7 (A3), 4.8 (A2), and 0.9 (A1) $\mathrm{t} \mathrm{m}^{-1} \mathrm{yr}^{-1}$. The low rates at A6, where stresses were relatively high (Fig. 12), was a consequence of the relatively high fraction of faster-settling material there (Table 4). The high rate at A2 was caused by mobile, slow-settling material and persistent mean flow. The transport rates at the site closest to the outfalls and the center of the effluent-affected deposit (A5) was slightly higher than surrounding rates at sites A3 and A6 because stresses were higher than those at A3 and sediment was more easily eroded and settled more slowly than sediment at A6.

Modeled transport directions (Table 5, column 4) were broadly aligned with mean current directions measured 3 mab (i.e., mostly alongshore toward the northwest). The cross-shelf and alongshore components were computed relative to the local alongshore direction. Local alongshore directions (brown lines in Fig. 12) were determined by the principal axis of current variation at sites $A 1, A 2, A 4, A A, A B$, and $A C$. Where the principal axes deviated significantly from the local trend in isobaths (sites $A 3$, A5, A6, A7, A8, A9, and AD), we used the trend of the isobaths. Cross-shelf transport is reported as positive seaward (generally southwest) and alongshore transport is positive toward the northwest (Table 5, columns 5 and 6 , respectively). There was a substantial cross-shelf component directed offshore at all sites except A2 and A8. Transport ranged between $32^{\circ}$ and $41^{\circ}$ offshore at the three PV sites closest to the outfalls (A3, A5, and A6; Table 5, column 7). Sediment transport was rotated to offshore relative to the mean northwestward flow, at most sites, including the three closest to the outfalls. This indicates that there was at least some correlation between offshore-directed flow and resuspension. It is likely that we have underestimated the amount 
Table 5

Summary of computed sediment-transport rates and statistics of bottom stresses.

\begin{tabular}{|c|c|c|c|c|c|c|c|c|c|}
\hline \multirow[t]{2}{*}{ Site } & \multirow{2}{*}{$\begin{array}{l}\text { Depth } \\
(\mathrm{m})\end{array}$} & \multicolumn{8}{|c|}{ Sediment-transport rate } \\
\hline & & $\begin{array}{l}\text { Magnitude } \\
\left(\mathrm{t} \mathrm{m}^{-1} \mathrm{yr}^{-1}\right)\end{array}$ & $\begin{array}{l}\text { Direction } \\
\left({ }^{\circ} \mathrm{T}\right)\end{array}$ & $\begin{array}{l}\text { Offshore } \\
\left(\mathrm{t} \mathrm{m}^{-1} \mathrm{yr}^{-1}\right)\end{array}$ & $\begin{array}{l}\text { Alongshore } \\
\left(\mathrm{t} \mathrm{m}^{-1} \mathrm{yr}^{-1}\right)\end{array}$ & $\begin{array}{l}\text { Alongshore } \\
\text { direction-transport } \\
\text { direction (deg.) }\end{array}$ & $\begin{array}{l}\text { Alongshore } \\
\text { direction-current } \\
\text { direction (deg.) }\end{array}$ & $\begin{array}{l}\text { 95th percentile } \\
\tau_{s f m}(\mathrm{~Pa})\end{array}$ & $\begin{array}{l}\text { 95th percentile } \\
\tau_{s f m} / \tau_{c r}\end{array}$ \\
\hline $\mathrm{A} 1$ & 65 & $0.9 \pm 1.0$ & 303 & 0.26 & 0.90 & 16 & -2 & 0.11 & 1.34 \\
\hline A2 & & $4.8 \pm 2.4$ & 307 & -0.69 & 4.71 & -8 & -2 & 0.12 & 1.48 \\
\hline A3 & & $1.7 \pm 0.7$ & 272 & 0.90 & 1.45 & 32 & 26 & 0.09 & 1.33 \\
\hline A5 & & $2.2 \pm 1.1$ & 271 & 1.21 & 1.87 & 33 & 7 & 0.11 & 1.55 \\
\hline A6 & & $1.1 \pm 0.6$ & 271 & 0.72 & 0.83 & 41 & 39 & 0.12 & 1.34 \\
\hline A8 & & $1.8 \pm 0.6$ & 326 & 0.13 & 1.78 & 4 & 34 & 0.13 & 1.37 \\
\hline $\mathrm{AA}$ & & $3.9 \pm 1.2$ & 264 & 2.01 & 3.37 & 31 & 22 & 0.16 & 1.76 \\
\hline $\mathrm{AC}$ & & $2.1 \pm 0.8$ & 226 & 0.65 & 1.98 & 18 & 5 & 0.14 & 1.49 \\
\hline A4 & 35 & $8.2 \pm 4.4$ & 287 & 1.52 & 8.10 & 11 & 12 & 0.26 & 3.33 \\
\hline A7 & & $16.8 \pm 6.7$ & 251 & 9.09 & 14.15 & 33 & 34 & 0.27 & 3.28 \\
\hline A9 & & $14.8 \pm 3.7$ & 279 & 6.32 & 13.36 & 25 & 25 & 0.26 & 3.15 \\
\hline $\mathrm{AB}$ & & $17.2 \pm 8.9$ & 234 & 13.96 & 10.00 & 54 & 48 & 0.28 & 3.35 \\
\hline $\mathrm{AD}$ & & $6.2 \pm 7.5$ & 208 & 4.87 & 3.79 & 52 & 36 & 0.26 & 3.09 \\
\hline
\end{tabular}

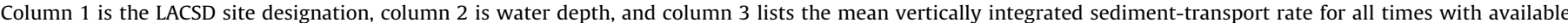

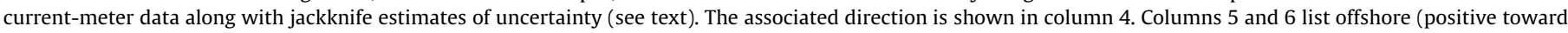

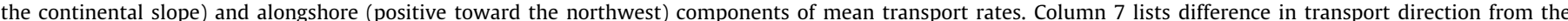

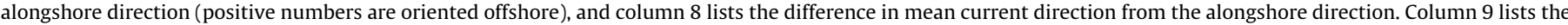
95th percentiles of bottom stress and column 9 lists the 95th percentiles of the ratio of bottom stress to fraction-weighted critical shear stress.

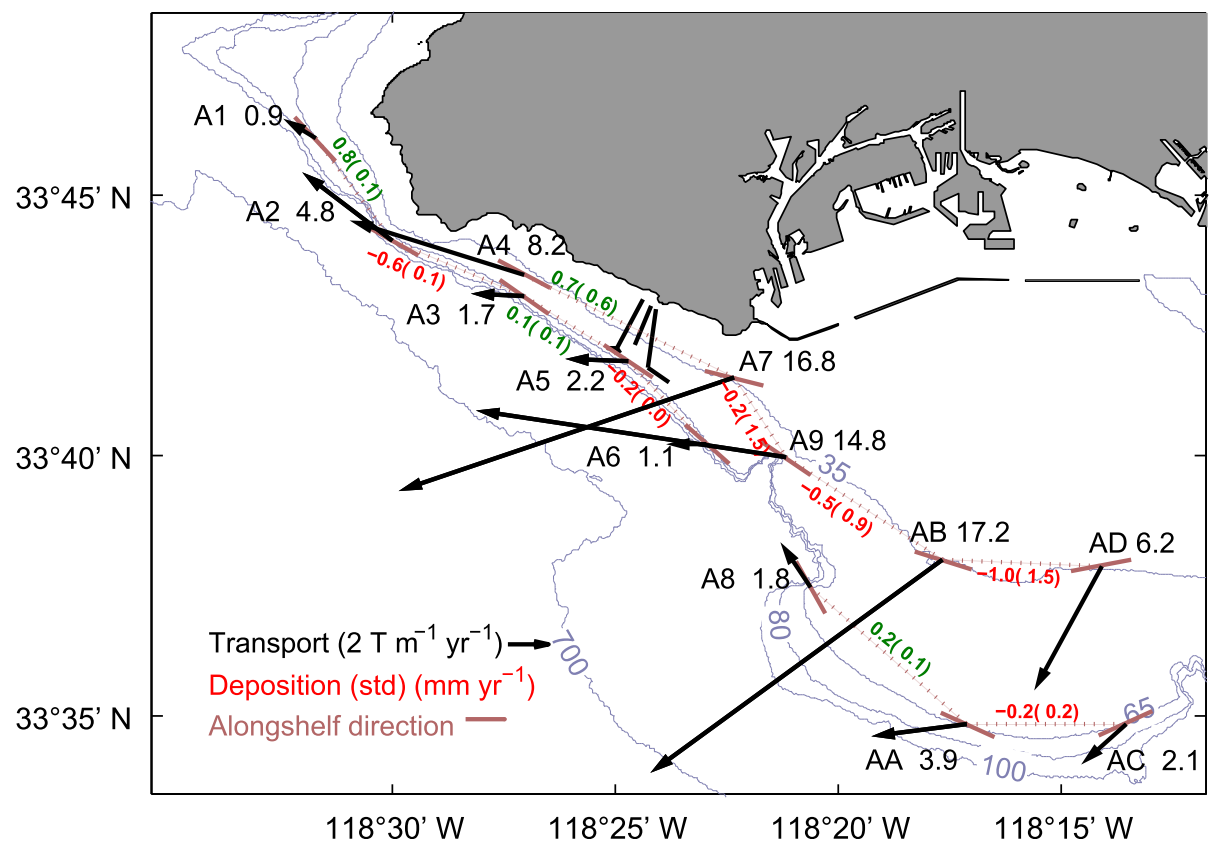

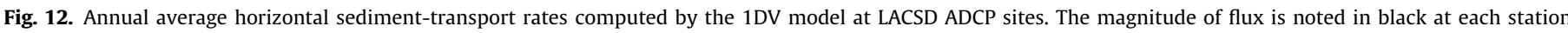

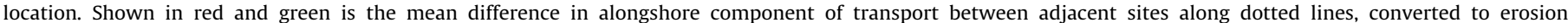

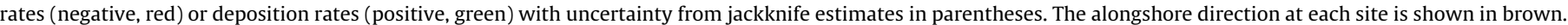

of offshore transport because (as discussed above) the model does not fully reproduce the counterclockwise rotation of mean flow toward the bed, where suspended sediment concentrations are highest.

We quantified trends in transport by calculating alongshelf gradients in sediment-transport rates (divergence) and converting these numbers to deposition rates. Mass conservation can be used to determine bed elevation change $\Delta \eta \mid \Delta t$ associated with gradients in horizontal sediment transport rate between two points as

$\frac{\Delta \eta}{\Delta t}=-\frac{1}{\rho_{B}}\left(\frac{F_{2}-F_{1}}{\Delta x}\right)$ where $F_{1}$ and $F_{2}$ are the alongshore vector components of sedimenttransport $\left(\mathrm{t} \mathrm{m}^{-1} \mathrm{~s}^{-1}\right)$ from site 1 toward site $2, \Delta x$ the alongshore distance between the two sites, and $\rho_{B}$ the dry bulk sediment particle density (approximately $1100 \mathrm{~kg} \mathrm{~m}^{-3}$ ). Uncertainty was propagated from the flux estimates. Eq. (6) is commonly employed with gridded values of $F$ to calculate erosion or deposition rates, but our sparse array of estimates precluded cross-shelf estimates. However, estimates of gradients in alongshore transport from the array might be meaningful, because currents and current low-frequency current variability is predominantly oriented alongshore (Fig. 9), and because there is alongshelf continuity of sediment characteristics over length scales of kilometers (Fig. 2, and Murray et al., 2002). 
Modeled alongshore gradients in transport rate between LACSD sites equated to deposition or erosion rates of less than $1 \mathrm{~mm} \mathrm{yr}^{-1}$ (green (deposition) and red (erosion) numbers on Fig. 12). The calculations indicated that alongshore transport on the southeastern portion of the PV shelf was greater at A5 than at A6, resulting in a net deposition rate of $-0.24 \pm 0.04 \mathrm{~mm} \mathrm{yr}^{-1}$ (erosion) over the $4 \mathrm{~km}$ separating the sites. Over the next reach, between $A 5$ and $A 3$, where alongshore transport rates were slightly lower, calculations suggested sediment accumulation at $0.09 \pm 0.09 \mathrm{~mm} \mathrm{yr}^{-1}$. Erosion $\left(-0.59 \pm 0.12 \mathrm{~mm} \mathrm{yr}^{-1}\right)$ was indicated between A3 and A2. Taken at face value, these calculations suggest that relatively small rates of deposition or erosion may be associated with alongshore variations in measured currents and estimated sediment characteristics.

\subsubsection{Scales for transport events}

We analyzed the modeled time series to determine time and length scales of transport events. Events were identified in the time series of magnitudes of depth-integrated sediment-transport rates $F$ (Eq. (6)), and defined as periods starting when $F$ exceeded an initial threshold $\left(0.09 \mathrm{~kg} \mathrm{~m}^{-1} \mathrm{~s}^{-1}\right)$ and ending when $F$ fell below that value. A minimum event duration of $3 \mathrm{~h}$ was required, and events separated by less than $6 \mathrm{~h}$ were combined.

Using these criteria, 196 events were identified in the model results for site A5. (Results from site A5 were typical of the 65-m sites on the PV shelf). Events at A5 lasted up to $105 \mathrm{~h}$, with median duration $6.25 \mathrm{~h}$ and mean duration $15 \mathrm{~h}$. Event-averaged transport rates ranged from 0.01 to $2.11 \mathrm{~kg} \mathrm{~m}^{-1} \mathrm{~s}^{-1}$, with median 0.11 and mean $0.17 \mathrm{~kg} \mathrm{~m}^{-1} \mathrm{~s}^{-1}$, and were not correlated with event duration $\left(r^{2}=0.11\right)$. Cross-shelf and alongshore transport distances $x_{e}$ and $y_{e}$ were calculated as the cumulative product of concentration-weighted velocities and model time interval $\Delta$ tover the event duration, as

$\left(x_{e}, y_{e}\right)=\sum_{n}\left(\frac{\left(F_{x}, F_{y}\right) \Delta t}{\sum_{z} \operatorname{ssc}(z) \Delta z}\right)$

where $n$ was number of model time steps in the event. The magnitude of transport distances $\sqrt{x_{e}^{2}+y_{e}^{2}}$ at A5 ranged from zero to $94 \mathrm{~km}$, with median 4 and mean $6.4 \mathrm{~km}$, and were well correlated with event duration $\left(r^{2}=0.65\right)$. Offshore $\left(x_{e}\right.$ negative) and northward alongshore $\left(y_{e}\right.$ positive) transport events were more frequent than onshore or southward alongshore events. Cross-shelf transport distances ranged from -24 to $+5 \mathrm{~km}$ and were skewed offshore with median $-0.4 \mathrm{~km}$ and mean $-1.6 \mathrm{~km}$. More than a quarter of the events resulted in offshore transport distances farther than $-2.5 \mathrm{~km}$. Alongshore transport distances were longer, ranging from -43 to $94 \mathrm{~km}$, and were bimodal with more (and longer) northward events. Median alongshore transport distance was $2 \mathrm{~km}$, with mean $2.3 \mathrm{~km}$.

\subsubsection{Seasonal and annual variation of sediment transport}

We compared modeled transport for winter and summer seasons and among years. Transport rates were higher in winter but transport directions were similar, except at sites on the southeast PV shelf, where summer transport trended more offshore. Although Fig. 8 clearly shows that waves were stronger in winters 2003 and 2006, net sediment transport was greater in winter 2001 because currents were more persistent. The mean transport rates on the PV shelf were $37 \mathrm{~kg} \mathrm{~m}^{-1} \mathrm{day}^{-1}$ in 2001 and 34.6 and $17 \mathrm{~kg} \mathrm{~m}^{-1}$ day $^{-1}$ in 2003 and 2006, respectively. Sediment transport rate was also higher in summer 2001 (mean rate of $13 \mathrm{~kg} \mathrm{~m}^{-1} \mathrm{day}^{-1}$ on the PV shelf) due to the stronger currents. Transport rates were lower in winter 2002 (mean rate of $15.6 \mathrm{~kg} \mathrm{~m}^{-1}$ day $\left.^{-1}\right)$ and in summer $2005\left(5.2 \mathrm{~kg} \mathrm{~m}^{-1}\right.$ day $\left.^{-1}\right)$ due to lower waves.
Seasonal deposition rates on the PV shelf showed trends similar to the long-term mean deposition rates for the entire period, with erosion between $\mathrm{A} 2$ and $\mathrm{A} 3\left(-2.06 \pm 0.65 \mathrm{~mm} \mathrm{y}^{-1}\right.$ in winter and $0.11 \pm 0.09 \mathrm{mmy}^{-1}$ in summer) and A5 and A6 $\left(-0.78 \pm 0.22 \mathrm{mmy}^{-1}\right.$ in winter and $-0.02 \pm 0.11 \mathrm{mmy}^{-1}$ in summer), with deposition elsewhere.

\section{Discussion}

This section discusses the sensitivity of results to model parameters and uncertainties in hydrodynamic forcing and sediment characteristics, and then evaluates our calculations as they pertain to the fate of the effluent-affected deposit. In Section 5.1, we define our skill metrics and use them to evaluate sensitivity to model parameters of our simulations of suspended-sediment concentrations (ssc) at sites B3 and B6. In Section 5.2, we take a broader view of model evaluation and present results from simulations using various combinations of sediment characteristics at the LACSD sites on the PV shelf. In Section 5.3, we discuss implications of temporal variation in erodibility. Finally, in Section 5.4, we discuss the importance of these model results for predicting the fate of the effluent-affected deposit.

\subsection{Sensitivity of model-data comparison at B6 to model parameters}

We evaluated the sensitivity of modeled sediment transport to sediment characteristics and other model parameters. We quantified sensitivity by evaluating changes in model skill in reproducing SSC measured by the transmissometer and ABS at sites B3 (Fig. 4) and B6 (Fig. 5). Skill was estimated using the Brier skill score (BSS; Brier and Allen, 1951; Sutherland et al., 2004), Willmott's (1981) index of agreement $d_{2}$, and the squared correlation coefficient $r^{2}$. The BSS was calculated as

$B S S=1-\frac{\sum\left(X_{m o d}-X_{o b s}\right)^{2}}{\sum\left(X_{o b s}-\bar{X}_{o b s}\right)^{2}}$

where $X$ is the tested variable (in this case, ssc), $\bar{X}$ its time average, and subscripts mod and obs denote modeled values and observations, respectively. The Willmott index of agreement was calculated as

$d_{2}=1-\frac{\sum\left|X_{\text {mod }}-X_{o b s}\right|^{2}}{\sum\left[\left|X_{\text {mod }}-\bar{X}_{o b s}\right|+\left|X_{o b s}-\bar{X}_{o b s}\right|\right]^{2}}$

The BSS ranges from negative infinity to one (perfect agreement). It is positive when the variation between the model and observations is less than the variability in the observations alone. Weather forecasters find that useful predictions have $B S S>0.2$ (Sutherland et al., 2004). The Willmott index of agreement ranges from zero (no model skill) to one (perfect agreement).

Tested parameters were critical shear stress $\tau_{c r}$, settling velocity $w_{s}$, erodibility parameters (slope and offset for B3 and $k_{1}$ and $k_{2}$ for $\mathrm{B} 6$ ), resuspension coefficient $\gamma_{0}$, and bottom roughness $z_{0}$. The influence of neglecting sediment-induced stratification (a model option, normally included) was also tested.

The results of the sensitivity analyses are summarized for site B3 in Table 6a and for site B6 in Table 6b. In each table, the top lines are baseline cases discussed in Section 3. At B3, the two baseline cases correspond to forcing at $1.41 \mathrm{mab}$ from the ADV at $\mathrm{B} 3$ and the forcing at $3 \mathrm{mab}$ from the ADCP at A3. At B6, the three baseline cases correspond to the PCADP forcing at $0.26 \mathrm{mab}$, the $\mathrm{ADCP}$ forcing at $9.3 \mathrm{mab}$ and the A6 ADCP at 3 mab. Model parameters that differed from the baseline case are indicated, and unchanged values are denoted with hyphens (-). Model 
Table 6

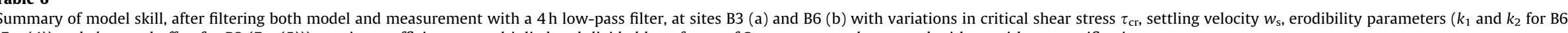
(Eq. (4)) and slope and offset for B3 (Eq. (5))), erosion coefficient $\gamma_{0}$, multiplied and divided by a factor of 2, extreme roughness, and with or without stratification.

\begin{tabular}{|c|c|c|c|c|c|c|c|c|c|c|c|c|c|}
\hline \multirow[t]{2}{*}{ (a) B3 } & \multirow[t]{2}{*}{ Case } & \multirow[t]{2}{*}{$\tau_{c r}(\mathrm{~Pa})$} & \multirow[t]{2}{*}{$w_{s}\left(\mathrm{~cm} \mathrm{~s}^{-1}\right)$} & \multirow[t]{2}{*}{ slope } & \multirow[t]{2}{*}{ offset } & \multirow[t]{2}{*}{$\gamma_{0}$} & \multirow[t]{2}{*}{$z_{0}(\mathrm{~m})$} & \multicolumn{3}{|l|}{$\mathrm{ABS}$} & \multicolumn{3}{|c|}{ Transmissometer } \\
\hline & & & & & & & & $r^{2}$ & $d_{2}$ & BSS & $r^{2}$ & $d_{2}$ & BSS \\
\hline 1 (baseline, $1.41 \mathrm{mab}$ ) & & Table 4 & Table 4 & 1.17 & 0.09 & $2 \times 10^{-4}$ & $9 \times 10^{-5}$ & 0.32 & 0.68 & -1.23 & 0.76 & 0.92 & 0.62 \\
\hline 2 (baseline, 3 mab, A3) & & - & - & - & - & - & - & 0.60 & 0.80 & -0.26 & 0.86 & 0.95 & 0.79 \\
\hline 3 & & (Table 4)/2 & - & - & - & - & - & 0.25 & 0.61 & -1.80 & 0.72 & 0.91 & 0.61 \\
\hline 4 & & (Table 4$) \times 2$ & - & - & - & - & - & 0.10 & 0.58 & -1.05 & 0.40 & 0.73 & -0.15 \\
\hline 5 & & - & (Table 4)/2 & - & - & - & - & 0.32 & 0.64 & -1.96 & 0.76 & 0.91 & 0.57 \\
\hline 6 & & - & $($ Table 4$) \times 2$ & - & - & - & - & 0.26 & 0.69 & -0.57 & 0.75 & 0.88 & 0.52 \\
\hline 7 & & - & - & 0.585 & - & - & - & 0.36 & 0.45 & -10.08 & 0.82 & 0.78 & -1.30 \\
\hline 8 & & - & - & 2.34 & - & - & - & 0.20 & 0.58 & -0.36 & 0.60 & 0.58 & -0.70 \\
\hline 9 & & - & - & - & 0.045 & - & - & 0.32 & 0.69 & -1.02 & 0.76 & 0.91 & 0.62 \\
\hline 10 & & - & - & - & 0.18 & - & - & 0.33 & 0.65 & -1.72 & 0.76 & 0.92 & 0.59 \\
\hline 11 & & - & - & - & - & $2 \times 10^{-5}$ & - & 0.21 & 0.64 & -0.13 & 0.67 & 0.67 & -0.22 \\
\hline 12 & & - & - & - & - & $2 \times 10^{-3}$ & - & 0.30 & 0.63 & -1.91 & 0.75 & 0.91 & 0.56 \\
\hline 13 & & - & - & - & - & - & $2.25 \times 10^{-5}$ & 0.32 & 0.69 & -1.07 & 0.77 & 0.92 & 0.63 \\
\hline 14 & & - & - & - & - & - & $2.3 \times 10^{-3}$ & 0.31 & 0.61 & -2.53 & 0.75 & 0.90 & 0.49 \\
\hline 15-no stratification & & - & - & - & - & - & - & 0.34 & 0.67 & -1.46 & 0.77 & 0.92 & 0.63 \\
\hline \multirow[t]{2}{*}{ (b) B6 } & \multirow[t]{2}{*}{ Case } & \multirow[t]{2}{*}{$\tau_{c r}(\mathrm{~Pa})$} & \multirow[t]{2}{*}{$w_{s}\left(\mathrm{~cm} \mathrm{~s}^{-1}\right)$} & \multirow[t]{2}{*}{$k_{1}$} & \multirow[t]{2}{*}{$k_{2}$} & \multirow[t]{2}{*}{$\gamma_{0}$} & \multirow[t]{2}{*}{$z_{0}(\mathrm{~m})$} & \multicolumn{3}{|l|}{ ABS } & \multicolumn{3}{|c|}{ Transmissometer } \\
\hline & & & & & & & & $r^{2}$ & $d_{2}$ & BSS & $r^{2}$ & $d_{2}$ & BSS \\
\hline 1 (baseline, $0.26 \mathrm{mab}$ ) & & Table 4 & Table 4 & 0.01 & 0.1 & $2 \times 10^{-4}$ & $9 \times 10^{-5}$ & 0.98 & 0.99 & 0.96 & 0.69 & 0.85 & -0.01 \\
\hline 2 (baseline, $9.3 \mathrm{mab}$ ) & & - & - & - & - & - & - & 0.72 & 0.87 & 0.66 & 0.42 & 0.63 & -0.16 \\
\hline 3 (baseline, $3 \mathrm{mab}$, A6) & & - & - & - & - & - & - & 0.68 & 0.88 & 0.35 & 0.26 & 0.62 & -1.75 \\
\hline 4 & & (Table 4)/2 & - & - & - & - & - & 0.95 & 0.96 & 0.78 & 0.70 & 0.82 & -0.38 \\
\hline 5 & & $($ Table 4$) \times 2$ & - & - & - & - & - & 0.98 & 0.92 & 0.78 & 0.68 & 0.85 & 0.36 \\
\hline 6 & & - & (Table 4)/2 & - & - & - & - & 0.97 & 0.96 & 0.76 & 0.70 & 0.80 & -0.69 \\
\hline 7 & & - & $($ Table 4$) \times 2$ & - & - & - & - & 0.98 & 0.99 & 0.96 & 0.69 & 0.85 & -0.01 \\
\hline 8 & & - & - & 0.005 & - & - & - & 0.95 & 0.90 & 0.76 & 0.72 & 0.85 & 0.42 \\
\hline 9 & & - & - & 0.02 & - & - & - & 0.98 & 0.93 & 0.54 & 0.69 & 0.71 & -2.57 \\
\hline 10 & & - & - & - & 0.05 & - & - & 0.98 & 0.99 & 0.97 & 0.69 & 0.85 & 0.01 \\
\hline 11 & & - & - & - & 0.2 & - & - & 0.98 & 0.99 & 0.96 & 0.69 & 0.85 & -0.03 \\
\hline 12 & & - & - & - & - & $2 \times 10^{-5}$ & - & 0.97 & 0.81 & 0.59 & 0.71 & 0.86 & 0.43 \\
\hline 13 & & - & - & - & - & $2 \times 10^{-3}$ & - & 0.96 & 0.96 & 0.78 & 0.71 & 0.85 & -0.04 \\
\hline 14 & & - & - & - & - & - & $2.25 \times 10^{-5}$ & 0.98 & 0.99 & 0.98 & 0.69 & 0.86 & 0.13 \\
\hline 15 & & - & - & - & - & - & $2.3 \times 10^{-3}$ & 0.97 & 0.89 & 0.14 & 0.71 & 0.76 & -1.41 \\
\hline 16 - no stratification & & - & - & - & - & - & - & 0.97 & 0.89 & 0.14 & 0.71 & 0.76 & -1.41 \\
\hline
\end{tabular}

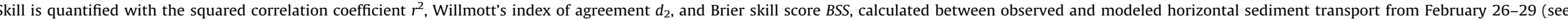
shadowed part in Figs. 5 and 6 ). 
simulations forced with the LACSD ADCPs A3 and A6 (near B3 and B6, respectively) were especially useful for evaluating our skill for the long-term calculations presented in Section 4, and important because the ADCP forcing is applied from farther above the bottom than our measurements. In some instances, this actually improved the skill.

The skill scores indicated that changed model parameters generally reduced model skill, but some parameters were less sensitive than others and, in the $k_{2}$ sensitivity case, model results improved slightly when this parameter was divided by two. The model results also improved slightly when an extremely small roughness value was used. We ranked the parameters in order of influence by calculating the average rank per tested parameters. The ranking (Table 7) indicated that model results were most sensitive to $k_{1}$ and the critical shear stress at B3 (cohesive; Eq. (4)) and most sensitive to slope and stratification at B6 (non-cohesive; Eq. (3)). Model results were relatively insensitive to stratification and $k_{2}$ at $\mathrm{B} 3$ and to offset at $\mathrm{B} 6$.

\subsection{Sensitivity of sediment-transport calculations to sediment characteristics and waves}

We evaluated the sensitivity of the sediment-transport calculations at the LACSD ADCP sites to assumptions about sediment erodibility. We used the results presented in Section 4 as our baseline, and evaluated changes in sediment-transport resulting from changes in model input at the 65-m sites on the PV shelf. We varied sediment erodibility by using the end members in sediment type (finest and easiest to erode: A3 and coarsest and most difficult to erode: A6) and assigning them uniformly to all LACSD sites. This allowed us to gauge how sensitive model results were to our somewhat uncertain characterization of sediments.

The results of these sensitivity runs are compared with our baseline results in Table 8 . Sediment-transport rates were

Table 7

Rank order of influence of model parameters on the horizontal sediment transport for the measurement period.

\begin{tabular}{|c|c|c|c|c|c|c|}
\hline & \multicolumn{3}{|l|}{ B3 } & \multicolumn{3}{|l|}{ B6 } \\
\hline & $r^{2}$ & BSS & $\mathrm{d}_{2}$ & $r^{2}$ & BSS & $\mathrm{d}_{2}$ \\
\hline$\tau_{c r}$ & 1 & 3 & 4 & 3 & 4 & 5 \\
\hline$w_{s}$ & 4 & 4 & 3 & 6 & 6 & 6 \\
\hline slope $/ k_{1}$ & 2 & 1 & 1 & 3 & 3 & 2 \\
\hline offset $/ k_{2}$ & 7 & 7 & 6 & 7 & 7 & 7 \\
\hline$\gamma_{0}$ & 3 & 3 & 2 & 2 & 4 & 4 \\
\hline$z_{0}$ & 6 & 5 & 5 & 4 & 3 & 3 \\
\hline strat & 6 & 6 & 6 & 4 & 1 & 1 \\
\hline
\end{tabular}

Lower numbers=higher influence. Erodibility parameters slope and offset (Eq. (3)) apply to site B3, and $k_{1}$ and $k_{2}$ (Eq. (4)) apply to site B6. generally lower when the difficult-to-erode sediment was used at all sites. The erosion rate between A5 and A3 fell to essentially zero, and the region between $A 6$ and $A 5$ became depositional. The erosion rate between $A 3$ and $A 2$ decreased to $1 / 3$ of the baseline value, and the deposition rate between $A 2$ and $A 1$ decreased to $1 / 4$ of the baseline value.

Sediment-transport rates were higher when we assigned more mobile sediment to all sites, especially at sites where sediment was difficult to erode in the baseline case (e.g. A2; Table 8). The easily erodible case indicated deposition between $A 6$ and $A 5$ and between $\mathrm{A} 5$ and $\mathrm{A} 3$. The erosion rates between $\mathrm{A} 3$ and $\mathrm{A} 2$ were increased by $50 \%$, and there was a slight increase in deposition rate between $\mathrm{A} 2$ and $\mathrm{A} 1$.

The sensitivity results presented in Table 8 , along with our observations from many other models runs (not presented) demonstrate that our earlier conclusion (that the region southeast of the outfalls does not supply enough sediment to replace material eroded from the effluent-affected deposit near the outfalls) is sensitive to the sediment properties we believe are appropriate for site A6. In other words, our inference that material removed from the thickest part of the effluent-affected deposit near A6 is not replaced by material transported from the southeast portion of the PV shelf near A5 is mostly based on the difference in sediment types at those two sites. This is consistent with earlier arguments by Sherwood et al. (2002).

We also performed model runs without waves (not shown) which resulted in smaller sediment-transport rates at all sites. This was expected, because wave-induced bottom stresses are important for sediment resuspension. However, there was essentially no change in the relative transport rates, so although the magnitudes of deposition rates were generally smaller, the patterns were unchanged. This was not entirely unexpected, because waves were similar at all 65-m sites, but it does indicate that the timing of wave enhancement of transport rates does not have a significant impact on relative transport rates.

Overall, these sensitivity analyses show that most of our interpretations are not especially sensitive to our uncertainties in model parameters. The exception to this is our inferred lack of sediment supply from the southeast part of the PV shelf, which does require that sediment at $A 6$ is relatively difficult to erode compared with that at A5. However, we have presented several lines of evidence to indicate that material on the southeastern portion of the shelf is, in fact, less mobile than sediment in the middle of the shelf (near sites A5 and A3).

\subsection{Temporal variation in erodibility}

Erosion-chamber measurements made on other continental shelves (Stevens et al., 2007; Law et al., 2008) and in estuaries

Table 8

Sensitivity of sediment transport estimates to sediment characteristics at the Palos Verdes sites.

\begin{tabular}{|c|c|c|c|c|c|c|}
\hline & \multicolumn{2}{|c|}{ Base case sediment } & \multicolumn{2}{|c|}{ Uniform difficult-to-erode sediment } & \multicolumn{2}{|c|}{ Uniform easily erodible sediment } \\
\hline & $\begin{array}{l}\text { Transport } \\
\left(\mathrm{t} \mathrm{m}^{-1} \mathrm{yr}^{-1}\right)\end{array}$ & $\begin{array}{l}\text { Deposition rate } \\
\left(\mathrm{mm} \mathrm{yr}^{-1}\right)\end{array}$ & $\begin{array}{l}\text { Transport } \\
\left(\mathrm{t} \mathrm{m}^{-1} \mathrm{yr}^{-1}\right)\end{array}$ & $\begin{array}{l}\text { Deposition rate } \\
\left(\mathrm{mm} \mathrm{yr}^{-1}\right)\end{array}$ & $\begin{array}{l}\text { Transport } \\
\left(\mathrm{t} \mathrm{m}^{-1} \mathrm{yr}^{-1}\right)\end{array}$ & $\begin{array}{l}\text { Deposition rate } \\
\left(\mathrm{mm} \mathrm{yr}^{-1}\right)\end{array}$ \\
\hline A1 & 0.9 & & 0.2 & & 1.6 & \\
\hline A2 & 4.8 & 0.8 & 1.3 & 0.2 & 6.3 & 1.0 \\
\hline A3 & 1.7 & -0.6 & 0.3 & -0.2 & 1.7 & -0.9 \\
\hline A5 & 2.2 & 0.1 & 0.4 & 0.0 & 2.3 & -0.1 \\
\hline A6 & 1.1 & -0.2 & 1.1 & 6.1 & 6.1 & 0.6 \\
\hline
\end{tabular}

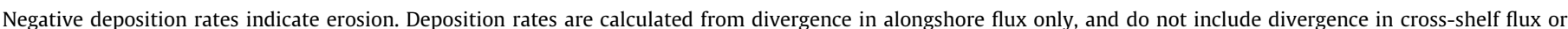
input from the water column, as discussed in Section 4.3.2. 
(Friedrichs et al., 2008; Dickhudt et al., 2009) show that erodibility can vary seasonally, sometimes changing the sign of spatial gradients. Preliminary evidence from new erosion-chamber measurements at Palos Verdes showed that erodibility varies temporally on the PV shelf as well. The data are sparse, and the patterns are not completely understood, but the region southeast of the outfalls was consistently the least mobile site on the PV shelf in February, 2008. Additional analyses of these data in the context of new bottom-boundary layer measurements made that winter may help us understand changes in erodibility and their implications for patterns of erosion and deposition on the PV shelf. For now, our conclusions are based on the simplifying assumption that neither biological activity nor sediment dynamics alters the distribution of sediment characteristics.

\subsection{Implications for the fate of the effluent-affected deposit}

Our original goal in performing these calculations was to take advantage of the long time series of current measurements and the better characterization of bottom sediment to estimate deposition rates from gradients in alongshore sediment-transport rates (revisiting the calculations of Sherwood et al., 2002 with better data). However, the results of our calculations here suggest that, although the alongshore gradients in sediment transport are consistent with those previous estimates, they may not capture the sedimentary process most important for determining the ultimate fate of the deposit.

A substantial fraction of the estimated transport is directed offshore. Material resuspended from the effluent-affected deposit is more likely to be lost from the shelf system or settle on the outer shelf where resuspension is less likely, than to supply downstream sites. Replacement of eroded material is more likely to come from inshore locations or vertical settling of widely dispersed sediment from coastal or riverine sources. This is because transport length scales are large, compared to shelf widths and many resuspension events are associated with internal waves that generate near-bottom speeds greater than $20 \mathrm{~cm} \mathrm{~s}^{-1}$ (Noble et al., 2009) with a strong offshore component. The long transport length scales mean that sediment resuspended along the $60-\mathrm{m}$ isobaths is likely to settle into deeper water as resuspension events wane. In addition, qualitative examination of the transport vectors and the bathymetry suggest that not all of the alongshore pathways implicit in our calculations exist. In particular, transport from the western San Pedro shelf is likely to be lost offshore as the shelf-break curves or be interrupted by the submarine canyon dividing the two shelves, so the large vector at site A9 and the smaller vectors at sites AA and AC are visually misleading. We suggest that the connected transport pathways for near-bottom transport are limited to the PV shelf between Pt. Fermin and Pt. Vicente (i.e., between LACSD sites A6 and A2).

Our inferred rates of deposition or erosion from alongshore gradients in sediment transport are an order of magnitude smaller than decade-scale estimates of accumulation rates inferred from burial rates of DDE profiles (Lee et al., 2002). Our estimates are also small compared with estimates of pre-outfall background sedimentation rates, which range from 1.7 to $2.3 \mathrm{~mm} \mathrm{yr}^{-1}$ (Sherwood et al., 2002; Alexander and Lee, 2009). If modern background sedimentation rates are similar, they would offset our estimates of erosion caused by differential transport.

The main differences in the calculations presented here from those of Sherwood et al. (2002, their Fig. 4) are that 1) they relied on a single year-long time series for currents, so the calculated gradients in sediment transport rates were caused only by spatial variations in sediment properties and 2) their spatial discretization of sediment variation was finer $(\sim 250 \mathrm{~m})$, so there were higher rates of more localized erosion and deposition. Our calculations here may be relatively attenuated because they were made between widely spaced sites ( $\sim 3-4 \mathrm{~km}$ apart), but they do not preclude locally higher rates of erosion associated with locally sharp gradients in sediment texture. One place where this might occur is between the two longest outfalls, where sediment texture changes abruptly (Fig. 2) from SE to NW. The calculations presented here add spatial variations in currents based on several years of data. Despite these improvements, our model results present only a part of the story. They do not include contributions from known sediment sources, including the Portuguese Bend Landslide, the outfalls (now almost zero), or regional supply.

\section{Conclusions}

We used the rich set of ADCP data collected by LACSD and a one-dimensional (vertical) numerical bottom-boundary layer model to estimate sediment-transport rates from three to six years at thirteen sites on the Palos Verdes (PV) and San Pedro shelves in Southern California. The model was evaluated against measurements made at two sites (B3 and B6) on the PV shelf in spring 2004. Model-data comparisons for this period indicate that the model slightly underestimates suspended-sediment concentrations, and does not capture fluctuations in ssc that we suspect are the result of advection, rather than local resuspension. More critically, the direction of sediment transport is uncertain: both near-bottom ( $<1 \mathrm{mab}$ ) current measurements at B6 from the PCADP and modeled transports forced with these currents are rotated offshore and counter clockwise, compared with ADCP current measurements 3-10 mab, which are oriented alongshore toward the northwest (Fig. 7). The model does not simulate this rotation, so when we force the model with the lowest bin in the LACSD ADCP data at A6 (3 mab), resulting modeled sedimenttransport directions also are more alongshelf toward the northwest. Because we do not have near-bed measurements for other times at A6 or for any of the other LACSD sites, we do not know whether similar changes in near-bed transport direction are common, but we must consider this uncertainty when interpreting the modeled transport directions.

Even with these uncertainties, the long-term ADCP data confirm important results from earlier and shorter-duration measurements: (1) near-bottom flow along the PV shelf is generally alongshelf and towards the northwest, with a significant offshelf component, (2) mean velocities at $65 \mathrm{~m}$ are largest at the two ends of the PV shelf, and smallest at sites A5 and A3, where the effluent-affected layer is thickest, and (3) principal axes of variation are aligned mostly alongshelf, but the PV shelf stations near and southeast of the outfalls have larger cross-shelf components.

The 1DV model helped us evaluate wave-current combined bed stresses at the ADCP locations. Near-bottom wave-orbital motions are greater in shallow water, so bottom stresses at all of the $35-\mathrm{m}$ sites are higher than bottom stresses at all of the $65-\mathrm{m}$ sites. Because our wave calculations are identical at all sites with the same depths, variation in bottom stresses among the 65-m sites are caused by differences in currents. Highest stresses were calculated on the ends of the PV shelf at sites A2 and A6. Bottom stresses were lowest at sites near the outfalls (A5), northwest of the outfalls (A3), and beyond Pt. Vicente (A1). The frequency of sediment mobilization, expressed as a ratio of the 95th percentile of bottom stress to the critical stress for erosion, was also lowest near the outfalls.

We quantified trends in transport by calculating alongshelf gradients in sediment-transport rates (divergence) and converting these numbers to deposition rates. The model results indicated 
that there was significantly more sediment being transported away from the northwestern portion of the effluent-affected deposit (away from A2) than was moving toward A2 from A3, suggesting that this northwesternmost part of the effluentaffected deposit may be eroding $\left(-0.6 \mathrm{~mm} \mathrm{yr}^{-1}\right)$. However, this contradicts long-term trends based on burial of DDE profiles (Lee et al., 2002), which indicate that this region was depositional, at least on average, between 1981 and 2001. It may be that material eroded from the PV coast, especially the toe of the Portuguese Bend landslide, has provided enough material to account for deposition despite the net transport out of this region.

Southeast of the outfalls (between A6 and A5), net erosion $\left(-0.2 \mathrm{~mm} \mathrm{yr}^{-1}\right)$ was indicated because less material was being supplied to this area than was transported away. This result is sensitive to our assumptions about sediment characteristics near A6, but several lines of evidence indicate that the material there was less mobile than material near A5 and A3. These results indicate that, in the absence of a supply of material from the outfalls or PV coast, the southeast edge of the effluent-affected deposit would erode at a slow rate and natural material would not be transported from the San Pedro shelf to replace it. However, the calculated erosion rates are low, and may be offset by natural background sedimentation. Localized erosion could still occur near abrupt transitions in sediment character. The low particle settling velocities and strong currents result in transport lengthscales that are long relative to the narrow width of the PV shelf, which combined with the significant offshore component in transport, means that resuspended sediment is likely to be transported off the shelf to settle in deeper water.

\section{Acknowledgments}

These studies were funded by the US Environmental Protection Agency Palos Verdes Superfund remediation project, managed by Carmen White; and by the US Geological Survey. LACSD currentmeter data were generously provided by Joe Meistrall, Alex Steele, and Joe Gully. SAIC performed many of the geotechnical measurements. The sediment cores were obtained by Dr. R. Wheatcroft, Oregon State University. The geostatistical analyses were performed by Dr. C. Murray, Pacific Northwest National Laboratory. The cumulative probability plots were made using modified scripts from the WAFO toolbox (WAFO-group, 2000; http://www.maths.lth.se/matstat/wafo/). Drs. C.T. Friedrichs, N. Ganju, and B. Butman provided valuable suggestions for improving earlier drafts of this paper. Use of firm and product names is for descriptive purposes only and does not imply endorsement by the US Government.

\section{References}

Alexander, C.R., Lee, H.J., 2009. Sediment accumulation on the Southern California Bight continental margin during the twentieth century. In: Lee, H.J., Normark W.R. (Eds.), Earth Science in the Urban Ocean: the Southern California Continental Borderland. Geological Society of America Special Paper 454, pp.193-226, doi:10.1130/2009.2454(2.4)

Bogucki, D., Dickey, T., Redekopp, L.G., 1997. Sediment resuspension and mixing by resonantly generated internal solitary waves. Journal of Physical Oceanography 27, 1181-1196.

Bothner, M., Gill, P.W., Boothman, W.S., Taylor, B.B., Karl, H.A., 1997. Chemical and textural characteristics of sediments at an EPA reference site for dredged material on the continental slope SW of the Farallon Islands. US Geological Survey Open-File Report 97-87, 46 pp.

Bothner, M., Buchholtz ten Brink, M., Manheim, F.T., 1998. Metal concentrations in surface sediments of Boston harbor-changes with time. Marine Environmental Research 45, 127-155.

Bray, N.A., Keyes, A., Morawitz, W.M.L., 1999. The California current system in the Southern California Bight and the Santa Barbara Channel. Journal of Geophysical Research 104, 7695-7714.
Brier, G.W., Allen, R.A., 1951. Verification of weather forecasts. Compendium of meteorology. American Meteorological Society, 841-848.

Dailey, M.E., Reish, D.J., Anderson, J.W., 1993. Ecology of the Southern California Bight: A Synthesis and Interpretation. University of California Press, Berkeley, CA, USA.

Dean, R.G., Dalrymple, R.A., 1991. Water Wave Mechanics for Engineers and Scientists. Advanced Series on Ocean Engineering, vol. 2. World Scientific, Singapore $353 \mathrm{pp}$.

Dickhudt, P.J., Friedrichs, C.T., Schaffner, L.C., Sanford, L.P., 2009. Spatial and temporal variation in cohesive sediment erodibility in the York River estuary, eastern USA: A biologically influenced equilibrium modified by seasonal deposition. Marine Geology 267, 128-140.

Dietrich, W.D., 1982. Settling velocity of natural particles. Water Resources Research 18 (6), 1615-1625.

Drake, D.E., 1994. Appendix D: results of grain size and settling analyses of sediment on the Palos Verdes margin. In: Lee, H.J. (Ed.), The Distribution and Character of Contaminated Effluent-Affected Sediment, Palos Verdes Margin, Southern California. Expert Report, US Geological Survey, Menlo Park, CA, $35 \mathrm{pp}$.

Drake, D.E., Cacchione, D.A., 1989. Estimates of the suspended sediment reference concentration $(\mathrm{Ca})$ and resuspension coefficient (gamma0) from near-bottom observations on the California shelf. Continental Shelf Research 9, 51-64.

Drake, D.E., Eganhouse, R., McArthur, W., 2002. Physical and chemical effects of grain aggregates on the Palos Verdes margin, southern California. Continental Shelf Research 22 (6-7), 967-986.

Edwards, B.D., Chezar, H., 1994. Camera survey of the Palos Verdes Shelf and Slope. In: Lee, H.J. (Ed.), The distribution and character of contaminated effluentaffected sediment, Palos Verdes margin, Southern California. Expert Report, US Geological Survey, Menlo Park, CA, pp. 63+appendices.

Eganhouse, R.P., Pontolillo, J., 2008. DDE in sediments of the Palos Verdes shelf, CA: in situ transformation rates and geochemical fate. Environmental Science \& Technology 42 (17), 6392-6398.

Emery, K.O., 1960. The Sea Off Southern California-A Modern Habitat of Petroleum. John Wiley, New York 366 pp.

Emery, W.J., Thomson, R.E., 2001. Data Analysis Methods in Physical Oceanography. Elsevier, Amsterdam 638 pp.

Friedrichs, C.T., Cartwright, G.M., Dickhudt, P.J., 2008. Quantifying benthic exchange of fine sediment via continuous, noninvasive measurements of settling velocity and bed erodibility. Oceanography 21 (4), 168-172.

Galloway, J.N., 1979. Alterations of trace metal geochemical cycles due to marine discharge of wastewater. Geochimica Cosmochimica Acta 43, 207-218.

Gardner, J.V., Dartnell, P., 2002. Multibeam Mapping of the Los Angeles, California Margin. US Geological Survey Open-File Report 02-162, Menlo Park, CA.

Gust, G., Muller, V., 1997. Interfacial hydrodynamics and entrainment functions of currently used erosion devices. In: Burt, N. (Ed.), Cohesive Sediments. Wiley, Chichester, UK, pp. 149-174.

Harris, C.K., Wiberg, P.L., 1997. Approaches to quantifying long-term continental shelf sediment transport with an example from the northern California STRESS mid-shelf site. Continental Shelf Research 17, 1389-1418.

Hendricks, T.J., 1978. Forecasting changes in sediments near outfalls. In: Bascom, W. (Ed.), Southern California Coastal Water Research Project Annual Report, 1978, Long Beach.

Hendricks, T.J., 1982. An advanced sediment quality model. In: Bascom, W. (Ed.), Southern California Coastal Water Research Project Biennial Report, 1981-1983, Long Beach.

Hendricks, T.J., 1984. Predicting sediment quality around outfalls. In: Bascom, W. (Ed.), Southern California Coastal Water Research Project Biennial Report, 1983-1984, Long Beach.

Hendricks, T.J., 1988. Development of methods for estimating the changes in marine sediments as a result of the discharge of sewered municipal wastewaters through submarine outfalls: part II - resuspension processes - draft copy, Southern California Coastal Water Research Project, Long Beach.

Hendricks, T.J., Eganhouse, R.P., 1992. Modification and Verification of Sediment Deposition Models, Southern California Coastal Water Research Project, Long Beach, California.

Hickey, B.M., 1992. Circulation over the Santa Monica-San Pedro Basin and Shelf. Progress in Oceanography 30, 37-115.

Jones, B., Noble, M.A., Dickey, T.D., 2002. Hydrographic and particle distributions over the Palos Verdes Continental Shelf: spatial, seasonal and daily variability. Continental Shelf Research 22, 945-965.

Kachel, N.B., Smith, J.D., 1989. Sediment transport and deposition on the Washington continental shelf. In: Landry, M.R., Hickey, B.M. (Eds.), Coastal Oceanography of Washington and Oregon. Elsevier Oceanography Series. Elsevier, Amsterdam, pp. 287-348.

Kayen, R.E., Lee, H.J., Hein, J.R., 2002. Influence of the Portuguese Bend landslide on the character of the effluent-affected sediment deposit, Palos Verdes margin, southern California. Continental Shelf Research 22, 911-922.

LACSD, 2004. Annual Report 2003; Palos Verdes Ocean Monitoring. County Sanitation Districts of Los Angeles County, Whitter, CA.

LACSD, 2006. Palos Verdes Flow Study; June 2006 Data Processing Summary, Sanitation Districts of Los Angeles County, Whittier, CA, 152pp.

Lacy, J.R., Sherwood, C.R., Wilson, D.J., A.Chisholm, T., Gelfenbaum, G.R., 2005. Estimating hydrodynamic roughness in a wave-dominated environment with a high-resolution acoustic Doppler profiler. Journal of Geophysical Research 110, C06014. 
Law, B.A., et al., 2008. Size sorting of fine-grained sediments during erosion: results from the western Gulf of Lions. Continental Shelf Research 28 (15), 1935-1946.

Lee, H., 1994. The Distribution and Character of Contaminated Effluent-Affected Sediment, Palos Verdes Margin, Southern California, US Geological Survey, Menlo Park, California.

Lee, H.J., Sherwood, C.R., Drake, D.E., Edwards, B.D., Wong, F., Hamer, M., 2002. Spatial and temporal distribution of contaminated, effluent-affected sediment on the Palos Verdes margin, southern California. Continental Shelf Research 22 (6-7), 859-880.

Logan, B.E., Steele, J.A., Arnold, R.G., 1989. Computer simulation of DDT distribution in Palos Verdes shelf sediments. Journal of Environmental Engineering 115 (1), 221-238.

Madsen, O.S., 1994. Spectral wave-current bottom boundary layer flows. Coastal Engineering 1994. In: Proceedings, 24th International Conference Coastal Engineering Research Council, pp. 384-398.

Morel, F.M.M., Westall, J.C., O'Melia, C.R., Morgan, J.J., 1975. Fate of trace metals in Los Angeles county wastewater discharge. Environmental Science and Technology 9 (8), 756-761.

Murray, C.J., Lee, H.J., Hampton, M., 2002. Geostatistical mapping of effluentaffected sediment distribution on the Palos Verdes shelf. Continental Shelf Research 22, 881-897.

Murray, C., Chien, Y.-J., 2006. Geostatistical Analysis of Sediment Erodibility on the Palos Verdes Shelf, Offshore Southern California. Letter Report prepared for the US Geological Survey, Pacific Northwest National Laboratory, Richland, WA.

Niedoroda, A.W., Swift, D.J.P., Reed, C.W., Stull, J.K., 1996. Contaminant dispersal on the Palos Verdes continental margin: III. Processes controlling transport, accumulation and re-emergence of DDT-contaminated sediment particles. The Science of the Total Environment 179, 109-133.

Noble, M.A., Xu, J.P., 2003. Observations of large-amplitude cross-shore internal bores near the shelf break, Santa Monica Bay, CA. Marine Environmental Research 56 (1-2), 127-149.

Noble, M.A., Ryan, H.F., Wiberg, P.L., 2002. The dynamics of subtidal poleward flows over a narrow continental shelf, Palos Verdes, CA. Continental Shelf Research 22 (6-7), 923-944

Noble, M.A., Rosenberger, K.J., Hamilton, P., Xu, J., 2009. Coastal ocean transport patterns in the central Southern California Bight. In: Lee, H.J., Normark, W.R. (Eds.), Earth Science in the Urban Ocean: the Southern California Continental Borderland. Geological Society of America Special Paper 454. pp. 193-226, doi:10.1130/2009.2454(3.3).

Pedlosky, J., 1987. Geophysical Fluid Dynamics, second ed. New York, SpringerVerlag $710 \mathrm{p}$

SAIC, 2005a. Data Report for the Summer 2004 Geotechnical Measurement Program Conducted on the Palos Verdes Shelf. SAIC Report Number 676, Science Applications International Corporation, 221 Third Street, Newport, RI 02840, San Diego, CA.

SAIC, 2005b. Data Report for the Summer 2004 Oceanographic Measurement Program Conducted on the Palos Verdes Shelf. SAIC Report Number 694 Science Applications International Corporation, 221 Third Street, Newport, RI 02840, San Diego, CA.

Sanford, L.P., Maa, J.P.Y., 2001. A unified erosion formulation for fine sediments. Marine Geology 179 (1-2), 9-23.

Schaaff, E., Grenz, C., Pinazo, C., Lansard, B., 2006. Field and laboratory measurements of sediment erodibility: a comparison. Journal of Sea Research $55,30-42$.

Sherwood, C.R., Hibler, L.F., 1994. Appendix D: Palos Verdes shelf wave modeling. In: Drake, D.E., Sherwood, C.R., Wiberg, P.L. (Eds.), Predictive Modeling of the Natural Recovery of the Contaminated, Effluent-Affected Sediment, Palos
Verdes Margin, Southern California. Battelle Marine Sciences Laboratory, Sequim, Washington, pp. 42 pp.+appendices.

Sherwood, C.R., Drake, D.E., Wiberg, P.L., Wheatcroft, R.A., 2002. Prediction of the fate of p, $\mathrm{p}^{\prime}$-DDE in sediment on the Palos Verdes Shelf, California, USA Continental Shelf Research 22 (6-7), 1025-1058.

Sherwood, C.R., Ferré, B., Eganhouse, R. P, Wiberg, P. L., 2006a. Evolution of the contaminated sediment deposit on the Palos Verdes (CA) Shelf: physical chemical, and biological processes. Presented at the Eastern Pacific Ocean Conference, Mt. Hood, Oregon, pp. 27-30.

Sherwood, C.R., Lacy, J.R., Voulgaris, G., 2006b. Shear velocity estimates on the inner shelf off Grays Harbor, Washington, USA. Continental Shelf Research 26 (17/18), 1995-2018.

Smith, J.D., 1977. Modeling of sediment transport on continental shelves. In: Goldberg, E.D., McCave, I.N., O'Brien, J.J., Steele, J.H. (Eds.), The Sea. WileyInterscience, New York, pp. 539-577.

Smith, J.D., McLean, S.R., 1977. Spatially averaged flow over a wavy surface. Journal of Geophysical Research 82 (12), 1735-1746.

Sternberg, R.W., 1967. Measurements of sediment movement and ripple migration in a shallow marine environment. Marine Geology 5, 195-205.

Stevens, A.W., Wheatcroft, R.A., Wiberg, P.L., 2007. Seabed properties and sediment erodibility along the western Adriatic margin, Italy. Continental Shelf Research 27 (3-4), 400-416

Stull, J.K., Swift, D.J.P., Niedoroda, A.W., 1996. Contaminant dispersal on the Palos Verdes continental margin: I. Sediments and biota near a major California wastewater discharge. The Science of the Total Environment 179, 73-90.

Sutherland, J., Peet, A.H., Soulsby, R.L., 2004. Evaluating the performance of morphological models. Coastal Engineering 51, 917-939.

WAFO-group, 2000. WAFO-A Matlab Toolbox for Analysis of Random Waves and Loads-A Tutorial. Math. Stat., Center for Math. Sci., Lund University, Lund, Sweden.

Wiberg, P.L., Harris, C.K., 2002. Desorption of p,p'-DDE from sediment during resuspension events on the Palos Verdes Shelf, California: a modeling approach. Continental Shelf Research 22 (6-7), 1005-1023.

Wiberg, P.L., Smith, J.D., 1987. Calculations of the critical shear stress for motion of uniform and heterogeneous sediments. Water Resources Research 23 1471-1478.

Wiberg, P.L., Drake, D.E., Cacchione, D.A., 1994. Sediment resuspension and bed armoring during high bottom stress events on the northern California inner continental shelf: measurements and predictions. Continental Shelf Research 14 (10/11), 1191-1219.

Wiberg, P.L., Drake, D.E., Harris, C.K., Noble, M., 2002. Sediment transport on the Palos Verdes shelf over seasonal to decadal time scales. Continental Shelf Research 22 (6-7), 987-1004.

Wiberg, P.L., Sherwood, C.R., 2008. Calculating wave-generated bottom orbita velocities from surface wave parameters. Computers and Geosciences 34 1243-1262, doi:10.1016/j.cageo.2008.02.010.

Willmott, C.J., 1981. On the validation of models. Physical Geography 2 (2) 184-194.

Wright, L.D., Kim, S.-C., Friedrichs, C.T., 1999. Across-shelf variations in bed roughness, bed stress and sediment suspension on the northern California shelf. Marine Geology 154, 99-115.

Xu, J.P., Noble, M.A., 2009. Variability of the Southern California wave climate and implications for sediment transport. In: Lee, H.J. and Normark, W.R. (Eds.) Earth Science in the Urban Ocean: The Southern California Continenta Borderland. Geological Society of America Special Paper 254, pp. 171-191 doi:10.1130/2009.2454(3.2) 